\title{
Small modular reactor core design for civil marine propulsion using micro-heterogeneous duplex fuel. Part I: Assembly-level analysis
}

\author{
Syed Bahauddin Alam ${ }^{\mathrm{a}, \mathrm{b}, \mathrm{c}, *}$, Dinesh Kumar ${ }^{\mathrm{c}, \mathrm{d}}$, Bader Almutairi ${ }^{\mathrm{b}, \mathrm{e}}$, Palash Kumar Bhowmik ${ }^{\mathrm{e}}$, \\ Cameron Goodwin ${ }^{\mathrm{b}}$, Geoffrey T. Parks ${ }^{\mathrm{a}}$ \\ ${ }^{a}$ Department of Engineering, University of Cambridge, Cambridge, CB2 1PZ, United Kingdom \\ ${ }^{b}$ Rhode Island Nuclear Science Centre, 16 Reactor Rd, Narragansett, RI 02882, USA \\ ${ }^{c}$ French Alternative Energies and Atomic Energy Commission, 13115 Saint-Paul-lez-Durance, France \\ ${ }^{d}$ Department of Physics and Astronomy, Uppsala University, Sweden \\ ${ }^{e}$ Department of Nuclear Engineering, Missouri SETT, USA
}

\begin{abstract}
In an effort to de-carbonise commercial freight shipping, there is growing interest in the possibility of using nuclear propulsion systems. In this reactor physics study, we seek to design a soluble-boron-free (SBF) and low-enriched uranium (LEU) $\left(<20 \%{ }^{235} \mathrm{U}\right.$ enrichment) civil nuclear marine propulsion small modular reactor (SMR) core that provides at least 15 effective full-power-years (EFPY) life at $333 \mathrm{MWth}$ using $18 \%{ }^{235} \mathrm{U}$ enriched micro-heterogeneous $\mathrm{ThO}_{2}-\mathrm{UO}_{2}$ duplex fuel and $15 \%{ }^{235} \mathrm{U}$ enriched homogeneously mixed all- $\mathrm{UO}_{2}$ fuel. We use WIMS to develop subassembly designs and PANTHER to examine whole-core arrangements.

The assembly-level behaviours of candidate burnable poison (BP) materials and control rods are investigated. We examine gadolinia $\left(\mathrm{Gd}_{2} \mathrm{O}_{3}\right)$, erbia $\left(\mathrm{Er}_{2} \mathrm{O}_{3}\right)$ and $\mathrm{ZrB}_{2}$ integral fuel burnable absorber (IFBA) as BPs. We arrive at a design with the candidate fuels loaded into $13 \times 13$ assemblies using IFBA pins for reactivity control. Taking advantage of self-shielding effects, this design maintains low and stable assembly reactivity with relatively little burnup penalty. Thorium-based duplex fuel offers better performance than all- $\mathrm{UO}_{2}$ fuel with all $\mathrm{BP}$ options considered. Duplex fuel has $\sim 20 \%$ lower reactivity swing and, in consequence, lower initial reactivity than all- $\mathrm{UO}_{2}$ fuel. The lower initial reactivity and smaller reactivity swing make the task of reactivity control through BP design easier in the thorium-rich duplex core. For control rod design, we examine boron carbide $\left(\mathrm{B}_{4} \mathrm{C}\right)$, hafnium, and Ag-In-Cd alloy. All the candidate materials exhibit greater rod worth for the duplex design. For both fuels, $\mathrm{B}_{4} \mathrm{C}$ has the highest rod worth. In particular, one of the major objectives of this study is to offer/explore a thorium-based candidate alternative fuel platform for the proposed marine core. It is proven by literature reviews that the ability of the duplex fuel was never explored in the context of a single-batch, LEU, SBF, long-life SMR core. In this regard, the motivation of this paper is to observe the neutronic performance of the proposed duplex fuel with respect to the $\mathrm{UO}_{2}$ fuel and 'open the option' of designing the functional cores with both the duplex and $\mathrm{UO}_{2}$ fuel cores.
\end{abstract}

A companion paper will examine key physics and core safety analysis parameters in the whole-core environment. 
Keywords: Civil marine propulsion, Small modular reactor (SMR), Soluble-boron-free (SBF) operation, Long-life core, Micro-heterogeneous thorium-based duplex fuel, All- $\mathrm{UO}_{2}$ fuel, Burnable poison (BP), Reactivity swing, Initial reactivity suppression, Control rod worth

\section{Introduction}

Marine propulsion has been an important application of nuclear energy since the earliest days of power reactors. Nuclear propulsion research was first undertaken in the United States during the 1940s and has since yielded important engineering results, including the invention of the pressurized water reactor (PWR) and the development of important safety practices (Khlopkin and Zotov, 1997, Hirdaris et al., 2014a, Vergara and McKesson, 2002). Since the 1955 launch of the USS Nautilus, nuclear naval vessels have accrued over 12,000 reactor-years of operational experience, demonstrating that with effective technology and training, nuclear marine propulsion can be a safe and reliable option (Hirdaris et al., 2014a, Ragheb, 2011). The U.S. "Nuclear Navy" has a record of reliable power with no major radiation releases throughout 5400 reactor-years of operation (Hirdaris et al., 2014a, Vergara and McKesson, 2002). There are a number of laboratories in the U.S., such as Bettis and Knolls Atomic Power Laboratories, working to further develop naval nuclear propulsion technology.

U.S. naval reactors use very highly enriched uranium fuel, giving very long core lifetimes compared to civil nuclear power plant. Russia has long experience ( $\sim 60$ years) in designing and operating PWR-type reactors for nuclear-powered icebreakers. Historically Russian ships (e.g. OK-900, KLT-40) have utilised a cermet fuel with uranium enriched to more than $20 \%$ ${ }^{235} \mathrm{U}$ (Bukharin, 2006), but a new generation of icebreaker cores (e.g. KLT-40S, RITM-200) are reported to use cermet fuel consisting of zirconium-based alloy host material embedded with $\mathrm{UO}_{2}$ particles enriched to less than $20 \%{ }^{235} \mathrm{U}$ (Zverev et al., 2013). These reactors will have a relatively low maximum power output of $174 \mathrm{MWth}$, a low capacity factor (around $65 \%$ ) and require refueling every 7 years (Bukharin, 2006, Prasad et al., 2015). Furthermore, the 315 MWth reactor RITM-400 is currently at the advanced design stage.

There are several interconnected reasons for the immaturity of civilian nuclear propulsion. First, there are political barriers posed by popular antinuclear sentiment and the reluctance of shipyards and ports to accommodate nuclear vessels (Dedes et al., 2011, Kramer, 1962). Second, there exists no in-place infrastructure for nuclear maritime refueling, maintenance or security. Third, potential operators are deterred by the legal and regulatory uncertainty surrounding nuclear propulsion, which is further complicated by the international scope of the issue (Namikawa et al., 2011). Fourth, nuclear reactors are a costly and potentially risky option, requiring about twice the capital investment of comparable diesel engines (Aspelund et al., 2006). Finally, there are also technical and engineering challenges that nuclear ships face. These include: (1) Non-proliferation concerns, which require that ships use uranium with less than $20 \%$ enrichment; (2) The need for flexibility and high availability, which requires

\footnotetext{
*Corresponding author

Email address: syed.nuclear@cantab.net (Syed Bahauddin Alam)
} 
ships to have long refueling intervals and to be capable of easily varying power; (3) Safety and stability standards, requiring a high level of passive safety, security, and engineering simplicity for maritime operation with limited support capability. The engineering solutions to these problems are further constrained by the demands of the onboard environment, which include pitching and rolling, space/weight limitations, and safety/shielding concerns (Carlton et al., 2011).

Meeting these engineering objectives will require a sustained commitment to research and development. Some interest is presently being shown in the possible application of nuclear energy in marine propulsion. Growing concerns about global warming are poised to drive its progress. A nuclear-powered ship - be it a surface ship or a submarine - receives its propulsion energy from a nuclear power plant on board, and can be dubbed an "atomic engine" (Norton and Mrina, 1962, Dedes et al., 2011). The main advantages of nuclear marine propulsion are that atomic engines do not consume hydrocarbon-based fuel and oxygen, and produce no exhaust gas. Atomic engines are reliable, compact sources of energy that can operate for years without new fuel, and do not need to be accompanied by vulnerable fuel supply tankers (Hirdaris et al., 2014a). These benefits have motivated the development of atomic engines without too much concern regarding cost (Dedes et al., 2011, Schinas and Stefanakos, 2012, Aspelund et al., 2006). Economic concerns reduce if a nuclear ship can demonstrate excellent performance in terms of endurance and speed (Hirdaris et al., 2014a).

With increasing attention being given to greenhouse gas emissions arising from the burning of fossil fuels for international air and marine transport and the excellent safety record of nuclear-powered ships, renewed interest in marine nuclear propulsion is likely (Mitenkov et al., 2003). Looking at medium- to long-term options (Hirdaris et al., 2014a), given that hydrogen is not yet ready for shipboard installation (Aspelund et al., 2006), there is currently no solution that eliminates all emissions and no other solution that can offer significant $\mathrm{CO}_{2}$ reduction (Anger, 2010).

Reactor cores for civil marine applications would need to be fundamentally different from land-based power generation systems, which require regular refueling, and from reactors used in military vessels, as the fuel used could not conceivably be as highly enriched.

The first author's PhD research (Alam, 2018) builds on Masters and PhD projects by researchers from the University of Cambridge (Sun, 2014, Otto, 2013, Fan, 2012, Zhang, 2013) and the University of Manchester (Peakman, 2014). The principal objective of this PhD research was to design a soluble-boron-free (SBF), small modular reactor (SMR) core using low enrichment uranium (LEU) fuel $\left(<20 \%{ }^{235} \mathrm{U}\right)$ that provides at least 15 effective full-poweryears (EFPY) life at $333 \mathrm{MWth}$. There have been several past studies of homogeneously mixed $\mathrm{Th} / \mathrm{UO}_{2}$ fuel (Galperin et al., 2002) and heterogeneous seed-blanket arrangements (Kazimi et al., 1999, Todosow et al., 2005, Clayton, 1993). Homogeneously mixed $\mathrm{Th} / \mathrm{UO}_{2}$ fuel only exhibits promising performance in a single-batch core when the ${ }^{235} \mathrm{U}$ enrichment exceeds 20\% (Galperin et al., 2002, Otto, 2013). Previous studies have indicated that thorium's advantages are best realized in micro-heterogeneous and heterogenous geometries (MacDonald and Lee, 2004), but heterogeneous seed-blanket arrangements rely on being able to remove the seed region and replace it mid-life with fresh fuel (Kazimi et al., 1999, Todosow et al., 2005, Clayton, 1993), which is not compatible with single-batch operation. In contrast, 
the ability of duplex fuel to exploit the potential benefits of thorium in the context of a singlebatch, LEU, SBF, long-life SMR core is yet to be fully explored (Zhao, 2001, MacDonald and Lee, 2004). Therefore, in this reactor physics study we will evaluate the performance of micro-heterogeneous $\mathrm{ThO}_{2}-\mathrm{UO}_{2}$ duplex fuel ${ }^{1}$, loaded in a single-batch strategy for civil marine propulsion. To provide a basis for comparison, we also evaluate the performance of homogeneously mixed all- $\mathrm{UO}_{2}$ fuel. We seek to design cores of $333 \mathrm{MW}$ thermal power that will operate with long refueling intervals of (at least) 15 effective-full-power-years (EFPY). We consider PWR technology since this has a proven record in maritime applications, and SBF (Yoo and Hong, 2018) operation for operational simplicity. The elimination of soluble boron has advantages in terms of simplification (removal of pipes, pumps and purification systems), space saving, the elimination of the corrosive effects of soluble boron, and improved safety effects (improvement of the moderator temperature coefficient and elimination of an entire class of boron dilution accidents (Kim et al., 1998)). Additionally, there is concern that, if a ship relying on soluble boron for reactivity control were to sink, the dilution of the coolant with seawater could cause a criticality accident (Kusunoki et al., 2000, Kim and Kim, 2000).

One of the principal objectives of this paper is to investigate and understand the behaviour of candidate burnable poison (BP) choices and control rods in a high burnup/long-life, SBF environment for the candidate fuels. Therefore, reactivity control by three candidate burnable absorbers - gadolinia $\left(\mathrm{Gd}_{2} \mathrm{O}_{3}\right)$, erbia $\left(\mathrm{Er}_{2} \mathrm{O}_{3}\right)$ and $\mathrm{ZrB}_{2}$ integral fuel burnable absorber (IFBA) - has been investigated to identify which BP performs better in terms of initial reactivity suppression, reactivity swing and residual burnup penalty. In addition, control rod design is performed in different temperature and power conditions for three candidate control materials: boron carbide $\left(\mathrm{B}_{4} \mathrm{C}\right)$, hafnium $(\mathrm{Hf})$ and $\mathrm{Ag}-\mathrm{In}-\mathrm{Cd}$.

It is also important to address the main motivations behind this study:

1. The objective is not to establish or justify the superiority of the duplex fuel over the $\mathrm{UO}_{2}$ fuel. As addressed, the ability of the duplex fuel was never explored in the context of a single-batch, LEU, SBF, long-life SMR core. Therefore, it is indeed a strong motivation to understand the underlying physics of the alternative fuel platform (duplex fuel) and observe the neutronic performance of the proposed duplex fuel with respect to the $\mathrm{UO}_{2}$ fuel.

2. To obtain the satisfactory neutronic performance for both the candidate fuel cores and conclude which fuel provides the better neutronic characteristics.

3. The idea of this paper is not just to satisfy the safety parameters, but to successfully "open the option" of designing the proposed SBF, marine SMR core with both the duplex and $\mathrm{UO}_{2}$ fuel cores.

4. Higher local burnup is not considered as a constraint, instead, it is an objective for the design of long life core. For the purpose of this study, it is assumed that suitable materials that can withstand high burnup will be available for future use for the long life marine core.

\footnotetext{
${ }^{1}$ The term 'duplex' is referred as micro-heterogeneous $\mathrm{ThO}_{2}-\mathrm{UO}_{2}$ duplex fuel throughout this study.
} 
The scope of this paper (Part I) is limited to the design methods, fissile loading determination, and design and analysis of BPs and control rods for our proposed SBF marine PWR core. A companion paper (Alam et al., 2019c) will discuss the associated physics and core safety analysis parameters (reactivity feedback, axial offset and power peaking factors) in the whole-core environment.

\section{Proposed SMR core design specifications and constraints}

\subsection{Thermal power selection}

The required output power is one of the important parameters when performing core design calculations. From the literature and knowledge of commercial shipping, the power of larger ships varies from 50 MWe to 100 MWe (Ippolito, 1990, Fan, 2012, Otto, 2013, Sawyer et al., 2008). According to the previous studies on civil marine SMR core design, $100 \mathrm{MWe}$ shaft power is a good basis for design calculations (Sun, 2014, Otto, 2013, Fan, 2012, Zhang, 2013, Peakman, 2014). Considering standard thermal and mechanical efficiency of 30\%, this requires a reactor with approximately $333 \mathrm{MW}$ thermal power.

\subsection{Choice of core lifetime and power availability}

It is worthwhile addressing why 15 years life is realistic, especially for the civil propulsion. The target operational core lifetime has been chosen based on prior studies in the literatures. According to the studies conducted by Sawyer et al. (Sawyer et al., 2008) and Hirdaris et al. (Hirdaris et al., 2014b,a), nuclear-powered merchant ships would be both technically feasible and economically competitive with a core life of over 10 years. Other studies by Carlton et al. (Carlton et al., 2011), Dedes et al. (Dedes et al., 2011) and David (House, 2015) considered that refueling for civil marine propulsion would need to be undertaken at about 5 to 7 -year intervals. Therefore, for a merchant ship, unlike a military ship or submarine because of the higher levels of fuel enrichment permitted, refueling should be contemplated on about a 10 to 12-year cycle, depending on the actual level of enrichment deployed (Hirdaris et al., 2014b,a, McCord, 2013). Furthermore, it was assumed that it would not be possible to design a nuclear reactor using well-established materials capable of achieving a core life of more than $\sim 20$ years because various degradation mechanisms, such as corrosion, would render the reactor inoperable long before the $\sim 20$ year core life was achieved (Ippolito, 1990, McCord, 2013). However, considering the literature and studies related to the civil nuclear merchant ships, it was thought that a 15-year core life would perhaps be achievable (Sun, 2014, Otto, 2013, Fan, 2012, Zhang, 2013, Peakman, 2014). Since we have a motivation for utilizing LEU for this civil marine propulsion project, a 15 year core lifetime would fit well and can be easily accommodated with current and potential long maintenance periods every 5 or 7.5 years (Carlton et al., 2011, Dedes et al., 2011, House, 2015, Hirdaris et al., 2014b,a, Ippolito, 1990). It means that each ship would only need to undergo refueling once during its life, while satisfying the design constraint for our low power density marine cores. In addition, it is assumed that the number of ports which will be able to accommodate nuclear-power ship for the purpose of refueling will be much lower (Peakman, 2014, Alam, 2018). Therefore, it is desirable for the ports to accommodate the maximum number of 
ships. In addition, there are obvious uncertainties and possibilities that refueling would take longer than anticipated (Peakman, 2014). In this regard, it is desired that the ship runs for a longer period of time than the targeted core life in order to avoid scheduling conflicts in the port and become mothballed while waiting for the ports to become available. In addition, it seemed sensible to overestimate the capacity factor $(\mathrm{CF})$ of the reactor by a relatively small margin as it inherently makes the calculations more conservative, especially when considering fuel performance, which is highly dependent on burnup. In addition, a higher CF will lead to conservative estimates of the minimum enrichment required to operate the system for the targeted core life (Peakman, 2014, Otto, 2013). Therefore, a power availability of 1.0 is considered in this study. Considering the addressed facts, 15 full-power years (with $\mathrm{CF}=1$ ) is a standard suggested lifetime (Sawyer et al., 2008, Carlton et al., 2011) considering the neutronics and fuel performance issues. However, fuel performance is not considered in these papers and is out of the scope of our study.

\subsection{Maximum fuel burnup and constraints}

Although current PWR uranium fuel rods can typically achieve a pellet burnup of 70 GWd/tonne (Rossiter and M., 2011, Otto, 2013), it has been shown that thorium dioxide can withstand irradiation of 70-100 GWd/tonne (MacDonald and Lee, 2004, Otto, 2013). 15-EFPY fuel cycle leads to high discharge burnup of $100 \mathrm{GWd}$ /tonne, which are far beyond the current operating experience in PWRs. However, it will be many years before civil marine propulsion achieves widespread commercialisation, and rapid improvements in materials and fabrication can lead to permitting ever-higher burnup (Peakman, 2014, Alam, 2018, Otto, 2013) and thus a $100 \mathrm{GWd} /$ tonne limit is appropriate. Therefore, higher discharge burnup is not considered as a constraint (or limiting factor as with current commercial reactors) for the design of a long life core, instead, it is an objective. It is worthwhile addressing that for the purpose of this study, it is assumed that suitable materials and technology that can withstand prolonged core life and high burnup will be available for future use for the long life marine core (Alam et al., 2019b, Zainuddin, 2015, Shwageraus and Feinroth, 2011, Andrews et al., 2014, Sukjai and Kazimi, 2015). This is backed up by the rapid development of silicon carbide (SiC) as a promising future cladding (Alam et al., 2019a). Current studies by Idaho National Laboratory (Wu et al., 2014) and Oak Ridge National Laboratory (Powers et al., 2015) suggest that SiC possesses various potential benefits over Zr-based alloys, such as increased corrosion resistance and excellent stability to neutron irradiation.

\subsection{Fuel selection}

There have been several past studies of homogeneously mixed $\mathrm{Th} / \mathrm{UO}_{2}$ fuel (Galperin et al., 2002) and heterogeneous seed-blanket arrangements (Kazimi et al., 1999, Todosow et al., 2005, Clayton, 1993). Homogeneously mixed $\mathrm{Th} / \mathrm{UO}_{2}$ fuel only exhibits promising performance in a single-batch core when the ${ }^{235} \mathrm{U}$ enrichment exceeds $20 \%$ (Galperin et al., 2002, Otto, 2013). Previous studies have indicated that thorium's advantages are best realized in micro-heterogeneous and heterogenous geometries (MacDonald and Lee, 2004), but heterogeneous seed-blanket arrangements rely on being able to remove the seed region and replace it mid-life with fresh fuel (Kazimi et al., 1999, Todosow et al., 2005, Clayton, 
1993), which is not compatible with single-batch operation. In contrast, the ability of duplex fuel to exploit the potential benefits of thorium in the context of a single-batch, LEU, SBF, long-life SMR core is yet to be fully explored (Zhao, 2001, MacDonald and Lee, 2004). Therefore, in this study we will evaluate the performance of micro-heterogeneous $\mathrm{ThO}_{2}-\mathrm{UO}_{2}$ duplex fuel, loaded in a single-batch strategy. To provide a basis for comparison we also evaluate the performance of homogeneously mixed all- $\mathrm{UO}_{2}$ fuel.

\section{Design methods}

\subsection{Subassembly sizing}

Our subassembly sizing calculations use a $13 \times 13$ assembly design. For purposes of comparison, we began by considering a standard Westinghouse 4-loop PWR core, which has a fueled core area of $8.9 \mathrm{~m}^{2}$ and uses 193 assemblies with 264 pins in a $17 \times 17$ array (Winters, 2004). We found that the marine reactor requires a fueled core area of $3.36 \mathrm{~m}^{2}$, a $67 \%$ reduction in area (Alam, 2018, Alam et al., 2015). If 112 assemblies with a $13 \times 13$ pin array are used, we achieve this size reduction while reducing our freedom for subassembly design and core design equally (a $42 \%$ reduction in pins per assembly and a $42 \%$ reduction in assemblies per core). Fortuitously, 112 is a 'magic number' of squares that can be formed into the approximate shape of a circle (Fig. 1b). Thus, we begin with 112 assemblies with a $13 \times 13$ arrangement. In a Westinghouse $17 \times 17$ assembly, there are 24 control pins and one instrument tube (8.7\% of pin locations). We wish to maintain a similar ratio in our design, while maintaining octant symmetry to help reduce power peaking, so we have 16 control pins (9.5\% of pin locations) and 153 fueled pins.

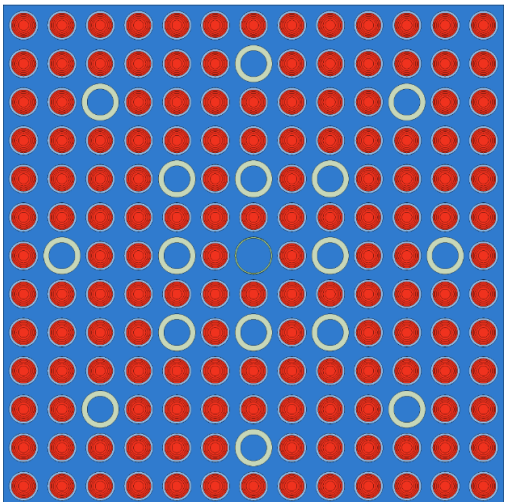

(a)

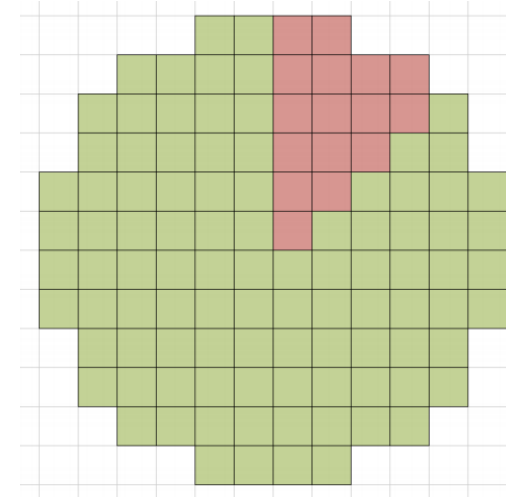

(b)

Fig. 1. Subassembly sizing: (a) $13 \times 13$ assembly geometry layout; (b) Schematic of a 112-assembly core, with one octant highlighted.

\subsection{Computational methods}

The subassembly design analysis employed the WIMS-10 lattice physics code using nuclear data from the JEF 2.2 database available from the IAEA (Newton et al., 2008). For each 
burnup step, WIMS completes a 172-group 'fine' solution to the transport equation in a smeared geometry. It then refines this solution using a few-group calculation in a precise geometry. In this study, we used a 6 energy group structure, as shown in Table 1 . It is important to address the calculation route for WIMS. In our study, WIMS module HEAD sets up cross-sections in library groups and PRES/CACTUS/RES sequence does a subgroup calculation of resonance shielding, where PRES sets up subgroup cross-sections at the fuel temperature, CACTUS calculates the subgroup fluxes by Method of Characteristics (MoC) and RES completes the subgroup calculation of resonance shielding. Multicell collision probability equations is solved by PERSEUS/PIP sequence. PERSEUS calculates multicell collision probabilities for the full problem in the geometry and PIP calculates neutron spectra for each material. The condensed cross-sections and flux spectrum calculated by COND module. BURNUP module carries out depletion of fuel at specified rating and timestep.

\begin{tabular}{|l|c|c|c|c|c|c|}
\hline Group & 1 & 2 & 3 & 4 & 5 & 6 \\
\hline Upper fine group & 1 & 23 & 46 & 93 & 136 & 153 \\
Lower fine group & 22 & 45 & 92 & 135 & 152 & 172 \\
Upper (eV) & $19.64 \times 10^{6}$ & $820.85 \times 10^{3}$ & $9.12 \times 10^{3}$ & 4.00 & $625 \times 10^{-3}$ & $140 \times 10^{-3}$ \\
Lower (eV) & $820.85 \times 10^{3}$ & $9.12 \times 10^{3}$ & 4.00 & $625 \times 10^{-3}$ & $140 \times 10^{-3}$ & $110 \times 10^{-6}$ \\
\hline
\end{tabular}

Table 1. 6-group WIMS energy structure.

The advanced 3D nodal code PANTHER (Hutt, 1992) is used for whole-core analysis and design. PANTHER imports few-group nuclear data from WIMS. Using the LED output module, WIMS homogenizes the neutronic data for a subassembly and exports a 'flat file' that is readable by PANTHER. This allows the user to load subassemblies prepared in WIMS into PANTHER in order to perform whole-core calculations. WIMS and PANTHER are thus interconnected in this study in performing subassembly design and whole-core analysis (Alam et al., 2019c). Flow chart of sample input files (Zainuddin and Lindley, 2014) for the WIMSbuilder, WIMS and PANTHER route is shown in Fig. 2.

\subsection{Design of fissile loading}

In $\mathrm{ThO}_{2}-\mathrm{UO}_{2}$ duplex fuel, the $\mathrm{UO}_{2}$ and $\mathrm{ThO}_{2}$ components are not blended together (as in homogeneous fuel) but are discretely interspersed on very small distance scales (Shwageraus et al., 2004). In our case, an individual fuel pin is composed of a uranium centre surrounded by an annulus of pure $\mathrm{ThO}_{2}$, as shown in Fig. 3.

It was assumed in the sizing analysis that the irradiation tolerance of the fuel (100 $\mathrm{GWd}$ /tonne) is the primary limiting factor in the core design. According to an MIT study $(\mathrm{Xu}, 2003)$, smaller cores are more sensitive to higher neutron leakage than that of the commercial PWR. As an example, for constant power density, a 500 MWth core will exhibit approximately twice leakage than that of the 3500 MWth core. The smaller core (500 MWth) will lose $7 \%$, If the latter (3500 MWth) loses 3.5\%. Furthermore, a recent SMR neutronic study by Oak Ridge National Lab (Brown et al., 2017) showed that 400 MWth SMR exhibits 6-8\% leakage depending on the core loading patters and other input parameters. 


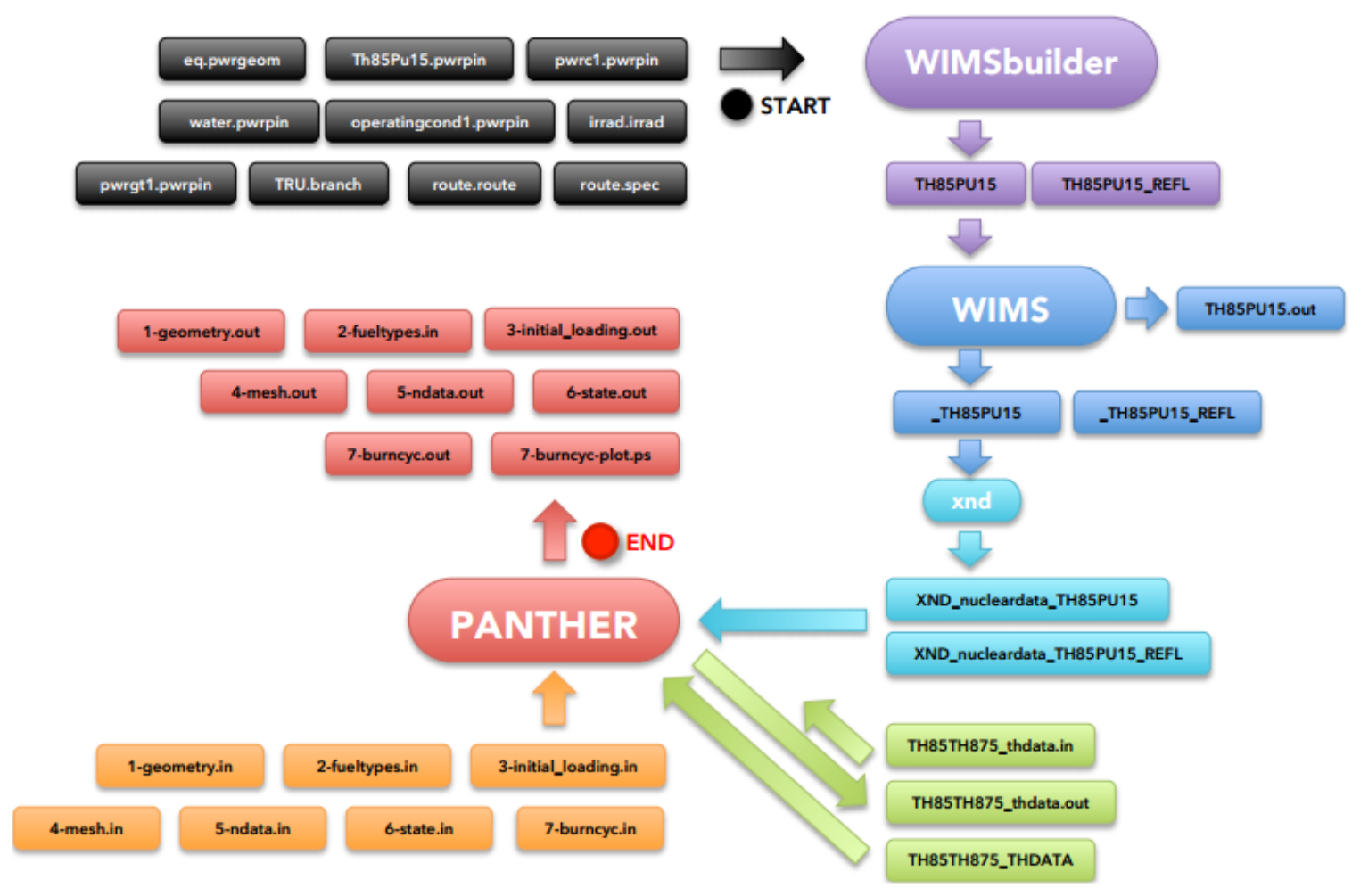

Fig. 2. Flow chart of input files for the WIMSbuilder, WIMS and PANTHER route used (Zainuddin and Lindley, 2014).

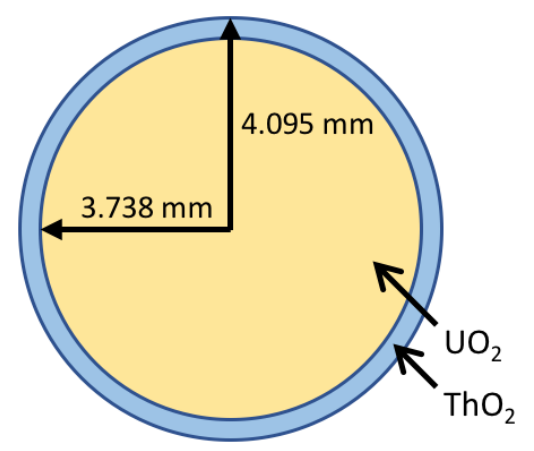

Fig. 3. Configuration of the micro-heterogeneous duplex $\mathrm{ThO}_{2}-\mathrm{UO}_{2}$ fuel. 
Since WIMS calculations assume an infinitely-large core and a small core is prone to larger leakage, we have assumed $7.5 \%$ leakage in this study.

In conventional PWR reactor, $4 \%$ leakage is considered while considering 2D lattice-level calculations (Alam, 2018). We have estimated from our core sizing analyses that considering our marine propulsion SMR core (Power $=333 \mathrm{MWth}$, Volume $=5.3 \mathrm{~m}^{3}$ ), leakage of $7.5 \%$ is considered conservative. This leakage has been checked with 3D whole-core nodal diffusion code PANTHER (Hutt, 1992). In the assembly level analysis for fresh fuel in WIMS (which assumes an infinitely-large core), discharge burnup is $95 \mathrm{GWd} /$ tonne considering $7.5 \%$ leakage, while whole-core exhibits the average burnup of $97 \mathrm{GWd} /$ tonne, which proves that $7.5 \%$ leakage is conservative for our SMR core design. The discharge burnup is therefore estimated from the point on the assembly burnup curve where the infinite multiplication factor, $k_{\infty}$, is 1.075

The fissile loadings of the duplex and $\mathrm{UO}_{2}$ fuels were determined from enrichment sensitivity studies, seeking values that keep the core critical for a burnup of $\sim 95 \mathrm{GWd} /$ tonne. It is clear from Figs. 4a and $4 \mathrm{~b}$ that, in order to achieve the desired discharge burnup, an initial enrichment of $15 \%$ and $18 \%{ }^{235} \mathrm{U}$ will be required for the $\mathrm{UO}_{2}$ and duplex fuels, respectively. Due to the higher thermal absorption cross-section of the fertile nuclide $\left.{ }^{232} \mathrm{Th}\right)$ in the duplex fuel, it requires higher enrichment than the all- $\mathrm{UO}_{2}$ fuel.

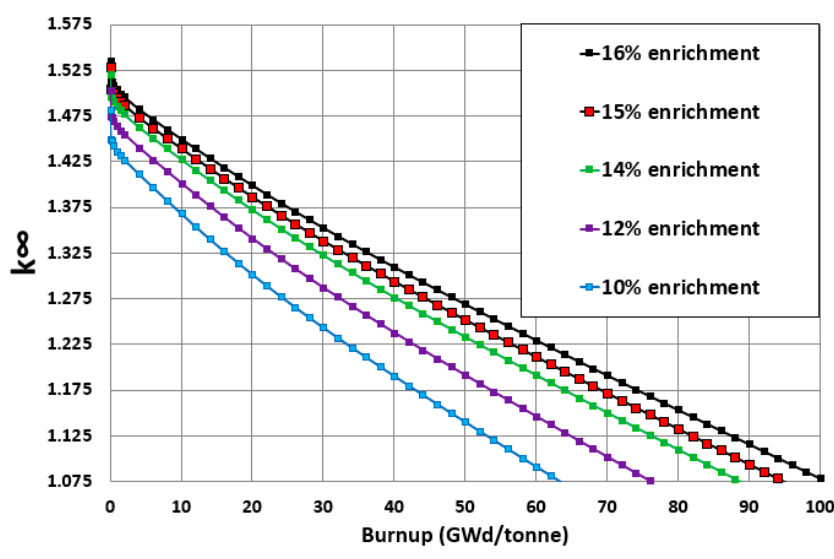

(a)

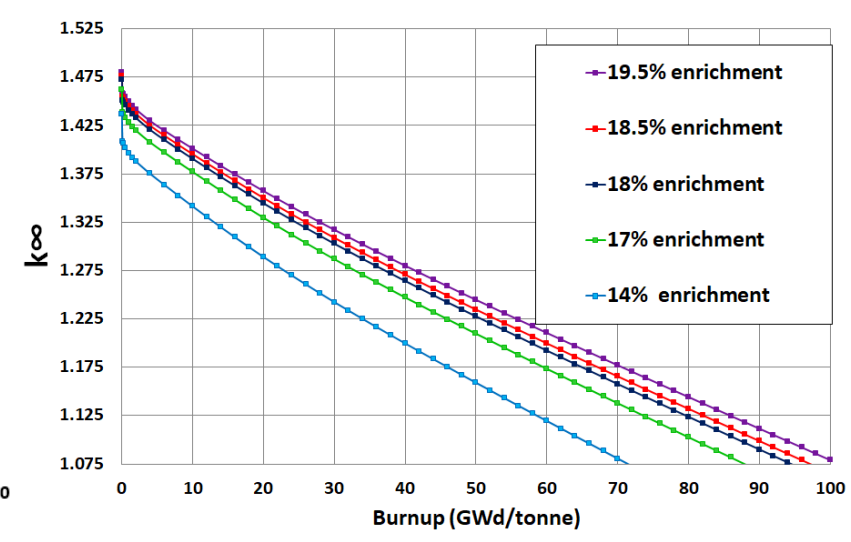

(b)

Fig. 4. Core depletion calculations for various fissile loadings: (a) $\mathrm{UO}_{2}$ fuel; (b) Duplex fuel.

The design parameters of the proposed marine core are shown in Table 2 (Alam, 2018, Alam et al., 2018a,b, 2016a,b,f,c,d,e, 2017b,a).

\subsection{Verification using WIMS, MONK \& Serpent}

It is helpful to verify the calculations for the fissile loadings of the candidate fuels to provide confidence in our assembly-level studies. Lattice physics calculations for the assemblies were therefore performed using the deterministic transport code WIMS, the Monte Carlo (MC) code Serpent (Leppänen and Pusa, 2009) and the hybrid MC code MONK (Long et al., 2015). MONK is a hybrid MC method when executed from inside WIMS program, using the discretized group structure given by WIMS instead of a continuous energy approach. 


\begin{tabular}{|l|c|}
\hline Parameter & Value \\
\hline Thermal power (MWth) & 333.33 \\
Minimum desired lifetime (years) & 15 \\
Assembly size & $13 \times 13$ \\
Control rods per assembly & 16 \\
Pin pitch (mm) & 12.65 \\
Fuel pellet diameter (mm) & 8.19 \\
Cladding thickness (mm) & 0.605 \\
Gap thickness $(\mathrm{mm})$ & 0.0498 \\
Number of assemblies & 112 \\
Fuel height $(\mathrm{m})$ & 1.79 \\
Core diameter $(\mathrm{m})$ & 1.97 \\
Pitch/diameter ratio & 1.33 \\
Hydrogen-to-heavy metal $(\mathrm{HHM})$ ratio & 3.99 \\
Assembly side length $(\mathrm{cm})$ & 16.45 \\
Assembly area $\left(\mathrm{m}^{2}\right)$ & 0.03 \\
Power density $\left(\mathrm{MW}^{2} \mathrm{~m}^{3}\right)$ & 63 \\
Average linear rating $(\mathrm{kW} / \mathrm{m})$ & 10 \\
\hline
\end{tabular}

Table 2. Design parameters of proposed marine core.

Each code has the capability to perform neutronic transport calculations using different methods to determine important neutronic parameters. A comparison between the three codes was conducted for a two-dimensional fuel assembly model (Fig. 1a). Fig. 5 shows the variation of $k_{\infty}$ with burnup for the candidate fuels with their final fissile loadings calculated with WIMS, MONK and Serpent using the JEF-2.2 nuclear data library.

Fig. 6 shows reactivity comparisons (in pcm) between the three codes at each burnup step. For both candidate fuels, excellent agreement is observed between the WIMS and MONK results with a maximum difference of $\sim 250 \mathrm{pcm}$. Slightly higher maximum differences of $\sim 350 \mathrm{pcm}$ are observed when comparing the results of the ANSWERS codes (Smith et al., 2011) (WIMS and MONK) and Serpent. The maximum differences are observed for individual burnup steps, whereas the average differences between pairs of codes are below $\sim 100 \mathrm{pcm}$. Condensation of the cross-sections from 172 to 6 groups in WIMS and MONK introduces a difference of $\sim 100 \mathrm{pcm}$. Serpent uses continuous data libraries while WIMS is limited to 172 energy groups and MONK is a hybrid MC code. Another contributing factor to these discrepancies is the condensation group scheme adopted by the COND module (Newton et al., 2008, Long et al., 2015) in WIMS and MONK. This module condenses the 172 energy groups into just 6 groups to reduce computation time. This introduces a discrepancy in comparison to Serpent, which uses hyperfine data libraries. The statistical errors in the Serpent and MONK calculations were $10 \mathrm{pcm}$. Taking all these factors into account, the discrepancies are deemed to be within an acceptable range.

The good agreement in these results offers reassurance that the deterministic reactor physics code WIMS can be used to provide reliable lattice physics results for SBF marine 


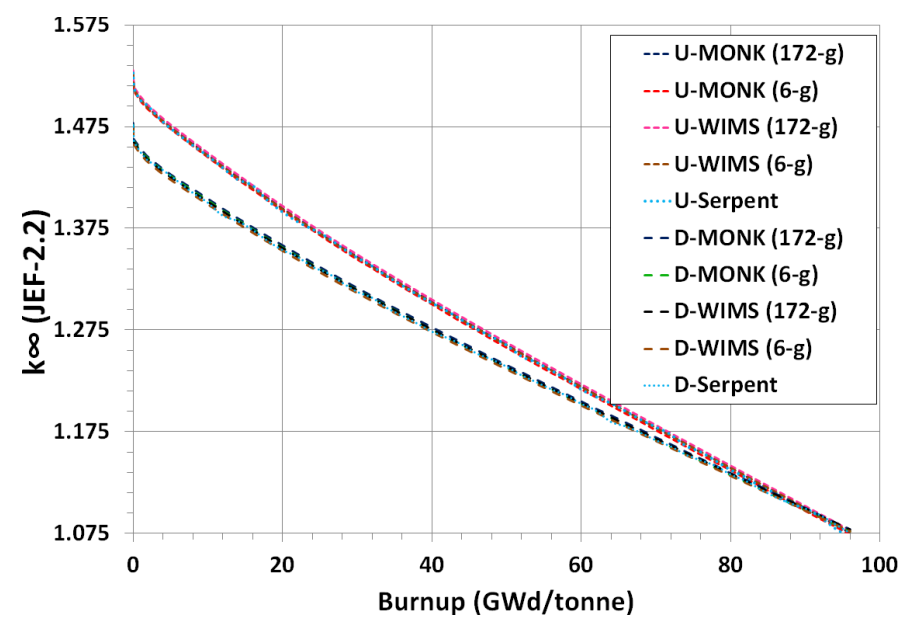

Fig. 5. $k_{\infty}$ vs. burnup for the candidate fuels calculated with WIMS, MONK and Serpent.

propulsion cores at much reduced computational cost compared to the MC code Serpent and hybrid MC code MONK.

\section{Neutron spectra}

The neutron spectra associated with the candidate fuels is of interest. In light water reactors, the neutron spectrum is determined by the balance between neutron moderation and absorption. Fig. 7 shows the neutron flux per unit lethargy normalized to unit total flux for the two candidate fuels at the beginning of life (BOL). The spectra are plotted in the WIMS 172-group structure. It can be observed that the $\mathrm{UO}_{2}$ fuel yields a marginally harder spectrum than the duplex fuel.

A higher "fertile capture-to-fissile absorption ratio" facilitates better fissile breeding (Alam, 2018, Alam et al., 2016b, Jagannathan et al., 2008). This ratio is shown for both candidate fuels at BOL in Fig. 8 for the entire neutron energy range and for the thermal energy range, in particular. It is apparent that this ratio is higher in the thermal energy range for the duplex fuel than the all- $\mathrm{UO}_{2}$ fuel.

\section{Fissile inventory ratio and conversion ratio}

In the duplex fuel, spatial separation between the fissile ${ }^{235} \mathrm{U}$ and the fertile ${ }^{232} \mathrm{Th}$ enables better moderation of the fission neutrons before they interact with the thorium. This enhanced thorium absorption promotes breeding and better reactivity control (Shwageraus et al., 2004). The fissile inventory ratio (FIR) quantifies the ratio of the fissile content of fuel to its initial fissile content and can be used to evaluate breeding ability more intuitively (Alam et al., 2018c, 2016e, Csom et al., 2012, György and Czifrus, 2015, Liu and Cai, 2013). We consider ${ }^{233} \mathrm{~Pa}$ and ${ }^{239} \mathrm{~Np}$ to be fissile materials for the purposes of calculating FIR for duplex and $\mathrm{UO}_{2}$ fuels, respectively, because ${ }^{233} \mathrm{~Pa}$ and ${ }^{239} \mathrm{~Np}$ will eventually decay into ${ }^{233} \mathrm{U}$ or ${ }^{239} \mathrm{Pu}$ after the assembly has been discharged (Liu and Cai, 2013). Fig. 9a shows that 


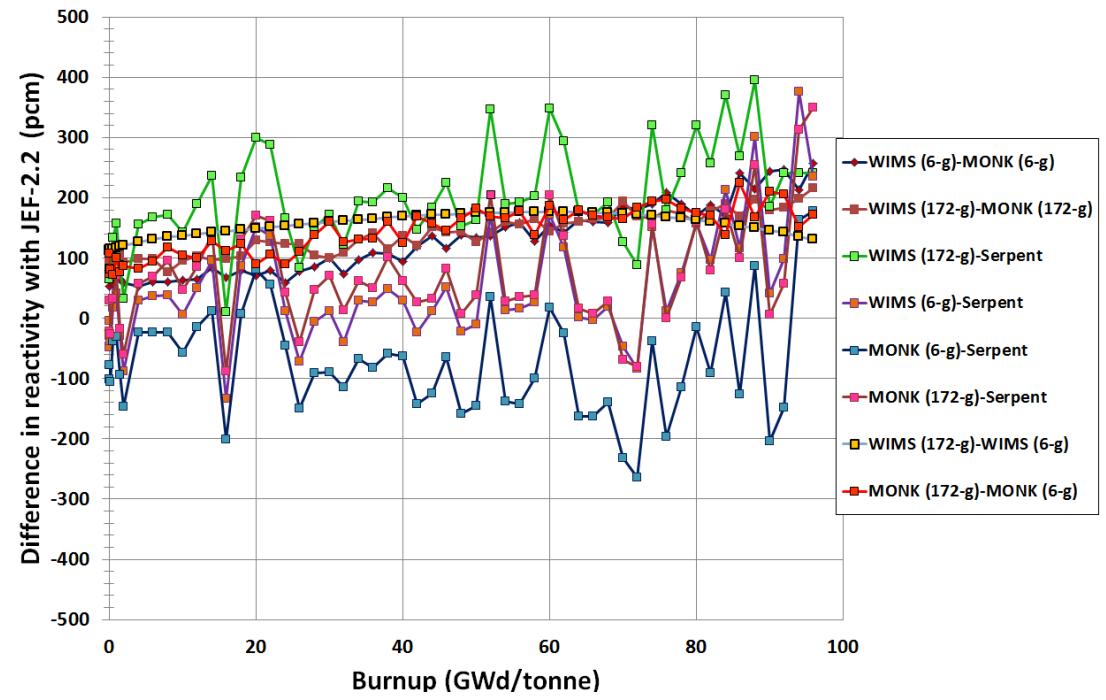

(a)

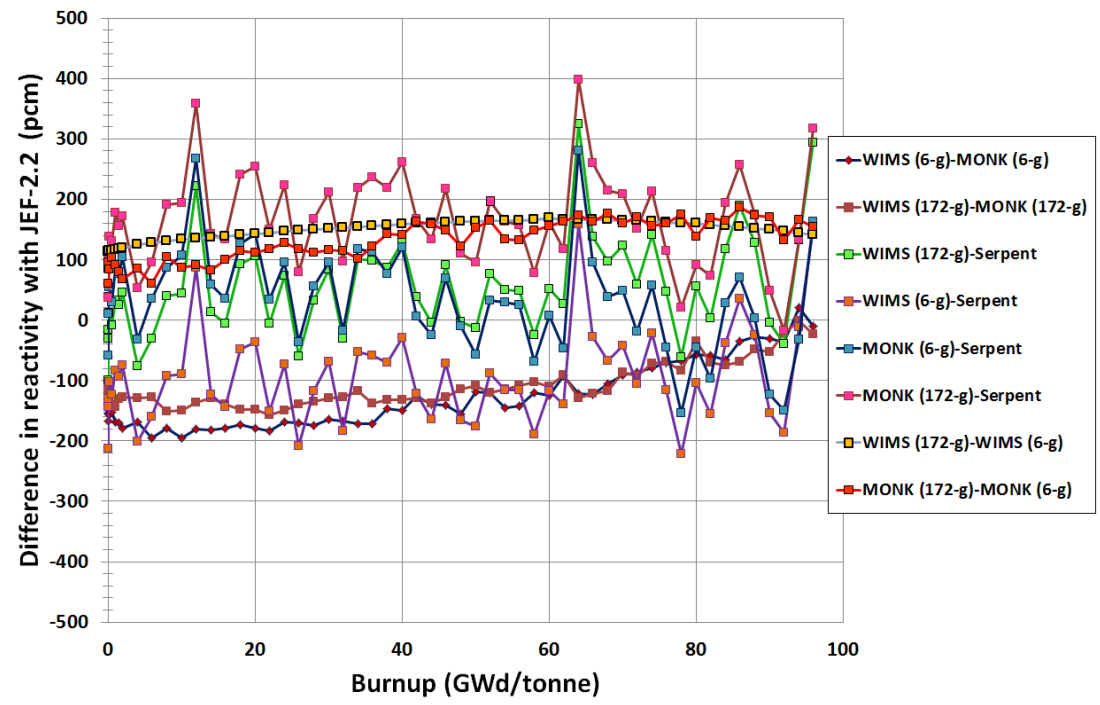

(b)

Fig. 6. Reactivity comparisons (pcm) between WIMS, MONK and Serpent: (a) $\mathrm{UO}_{2}$ fuel; (b) Duplex fuel. 


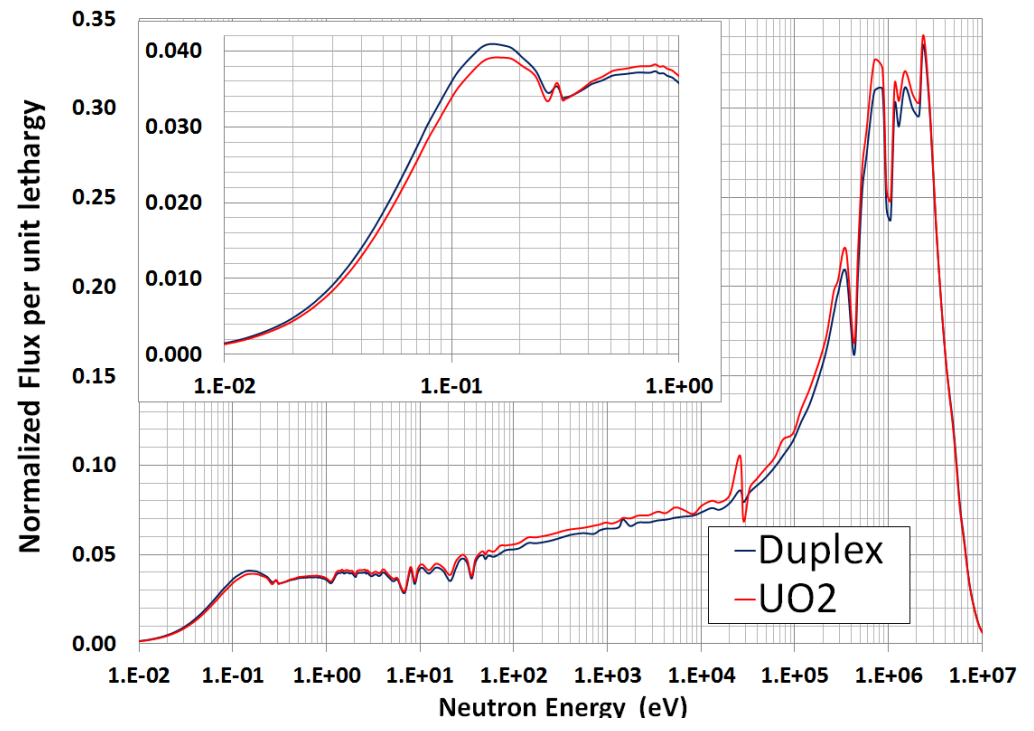

Fig. 7. Assembly averaged neutron spectra normalized per unit flux at BOL.

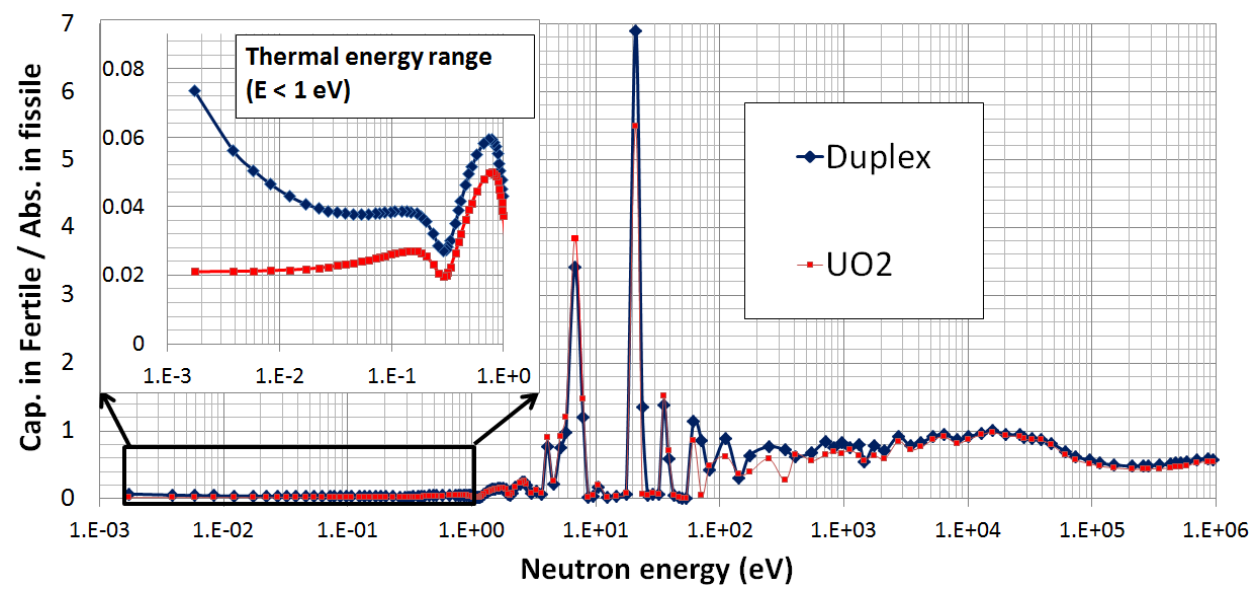

Fig. 8. Fertile capture-to-fissile absorption ratio at BOL. 
the FIR of the duplex fuel is higher than that for $\mathrm{UO}_{2}$, with the difference increasing with burnup. The FIR of duplex fuel is $\sim 5 \%$ higher than that for $\mathrm{UO}_{2}$ at $90 \mathrm{GWd} /$ tonne.

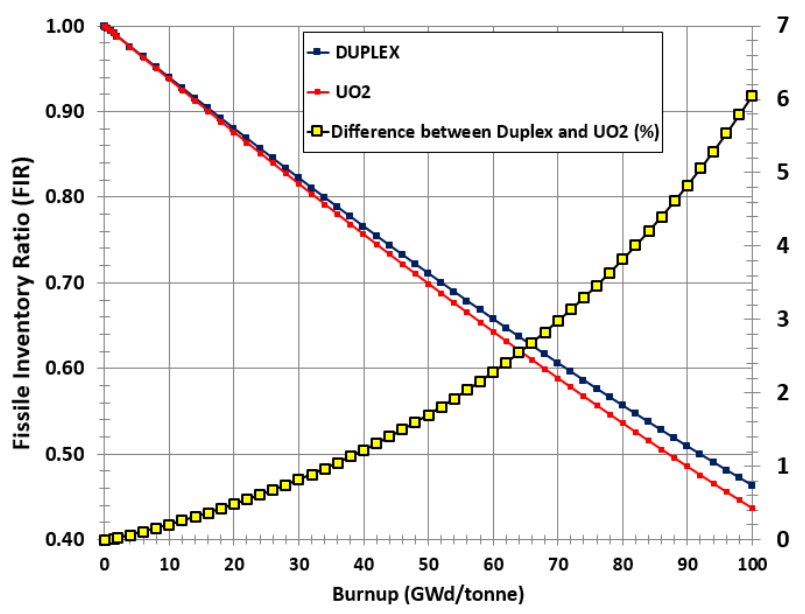

(a)

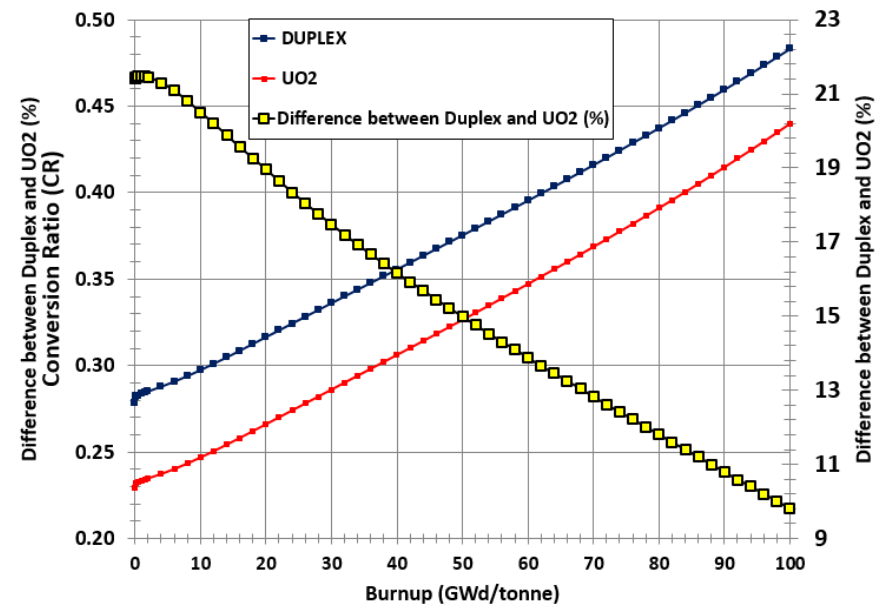

(b)

Fig. 9. Fissile inventory ratio and conversion ratio for the candidate fuels: (a) FIR; (b) CR.

The conversion ratio (CR), the ratio of the rates of production and consumption of fissile material, is another measure of the breeding potential of fuel and often a design goal (Alam et al., 2018c, Liu and Cai, 2013, Tsige-Tamirat, 2011). Fig. 9b shows that the CR of the duplex fuel is significantly higher than that of the $\mathrm{UO}_{2}$ fuel. It is important addressing that due to the higher thermal capture cross-section of ${ }^{232} \mathrm{Th}$ (for duplex fuel) than that of the ${ }^{238} \mathrm{U}$ (for $\mathrm{UO}_{2}$ fuel), duplex fuel exhibits efficient breeding of fissile ${ }^{233} \mathrm{U}$ and thus exhibits better breeding potential. A higher $\mathrm{CR}$ is helpful in achieving a longer core life and also reduces the reactivity swing experienced by the fuel over life, making the reactivity control of a SBF core easier.

\section{Burnable poison design}

In order to achieve the required lifetime, we have seen that the core requires a high fissile loading, significantly higher than in most civil reactors (Alam, 2018, Alam et al., 2018d, $2016 \mathrm{c}, \mathrm{d})$. As a direct consequence, the BOL reactivity is very high, and it is essential to have sufficient control measures to shut down the reactor quickly if necessary. As explained in Sect. 1, this core design will not use soluble boron. Relying too heavily on moveable rods would be imprudent for several reasons, including the expense of the rods, the negative effects on axial power-shape, the added complexity of the reactor's control system, and the heightened risk of rod-related accidents. Burnable poison therefore plays a major role in our reactivity control scheme. This section will focus on three types of BP loading: localized application of homogeneous poisons (smeared with fuels) for gadolinia $\left(\mathrm{Gd}_{2} \mathrm{O}_{3}\right)$ and erbia $\left(\mathrm{Er}_{2} \mathrm{O}_{3}\right)$, and coated neutron poison IFBA in the form of $\mathrm{ZrB}_{2}$. We aim to identify which fuel and $\mathrm{BP}$ combination performs best in terms of reactivity swing and initial reactivity suppression performance. Leakage is not considered in this assembly-level analysis. 


\footnotetext{
${ }^{2}$ Reactivity swing $\Delta k=k_{\max }-1.0$

${ }^{3}$ The ratio of flux at the surface to flux in the interior of the pin
} 
closely. Increased gadolinia concentration leads to lower reactivity swing and longer poison life for both fuels. The end-of-life (EOL) burnup penalty increases with the number of pins and with the $\mathrm{Gd}_{2} \mathrm{O}_{3}$ content.

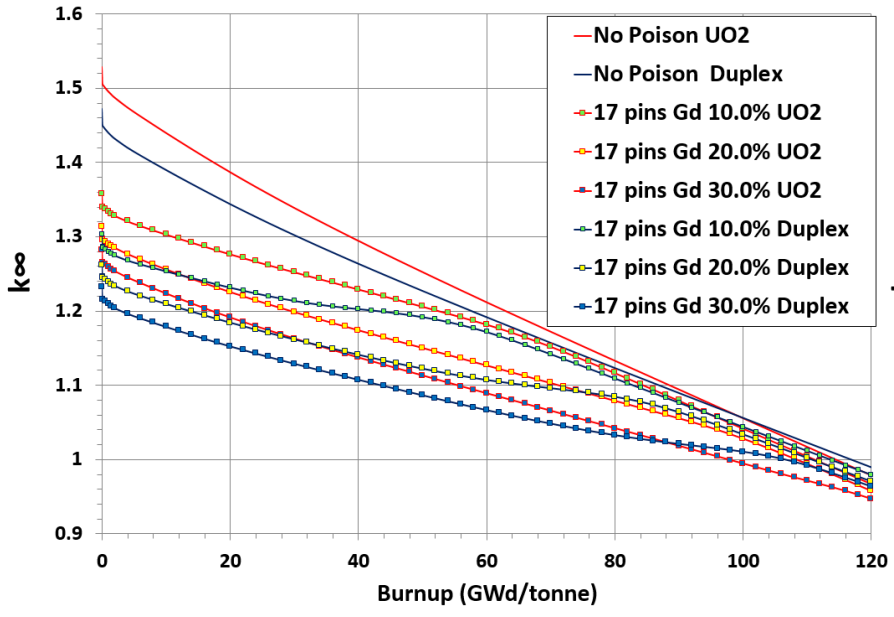

(a)

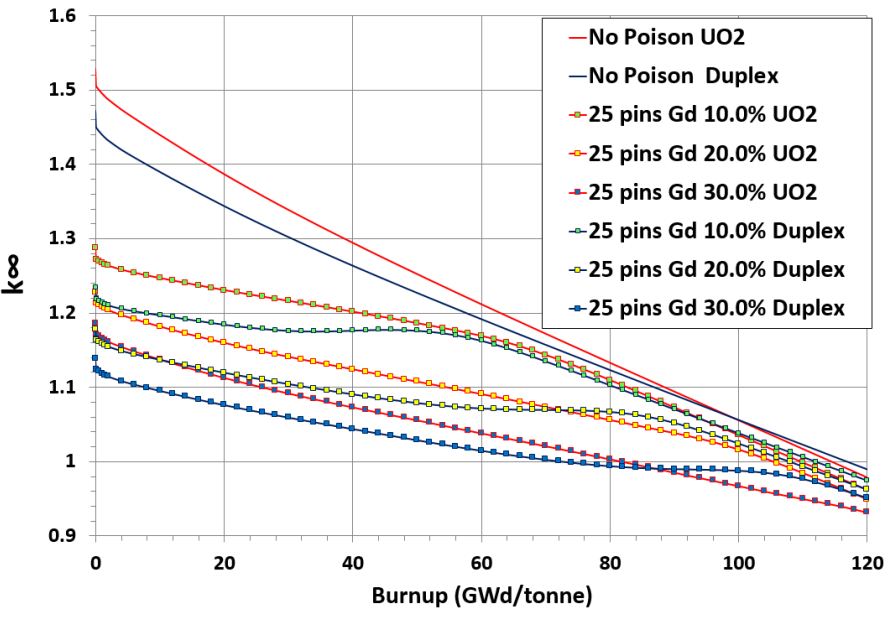

(b)

Fig. 11. $k_{\infty}$ vs. burnup for different $\mathrm{Gd}_{2} \mathrm{O}_{3}$ concentrations: (a) $17 \mathrm{BP}$ pins; (b) $25 \mathrm{BP}$ pins.

Fig. 12 shows the reactivity swing over the cycle for the various fuel and gadolinia combinations considered. It can be seen that the duplex fuel exhibits smaller (by $\sim 25 \%$ ) swings than the $\mathrm{UO}_{2}$ fuel in each case. The fissile content of the duplex fuel reduces more slowly due to the enhanced breeding of fissile material $\left({ }^{233} \mathrm{U}\right.$ in the duplex case vs. ${ }^{239} \mathrm{Pu}$ in the $\mathrm{UO}_{2}$ case). This effect accounts for the reduction in reactivity swing.

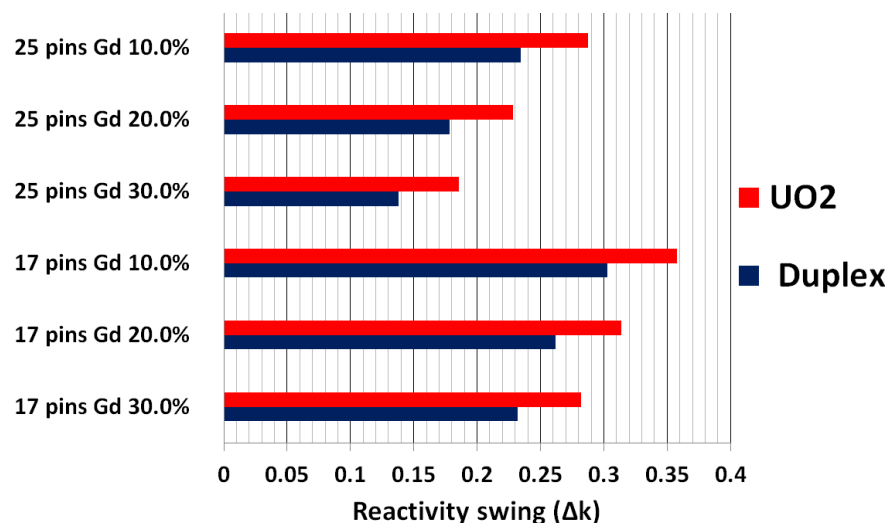

Fig. 12. Reactivity swing for different fuel $/ \mathrm{Gd}_{2} \mathrm{O}_{3}$ poison combinations.

Fig. 13 compares the capture rates per unit lethargy for both candidate fuels for the 25 pins with $30 \% \mathrm{Gd}_{2} \mathrm{O}_{3}$ cases. It can be seen that the gadolinia reaction rate per unit lethargy peaks at $\sim 0.10 \mathrm{eV}$ for both fuels. It can be seen that the capture rate is higher in duplex fuel at $\mathrm{BOL}$ than in $\mathrm{UO}_{2}$ in the thermal energy range for gadolinia, which explains the better 
reactivity hold-down. Capture rate has been observed only at BOL since it explains the initial reactivity hold-down.

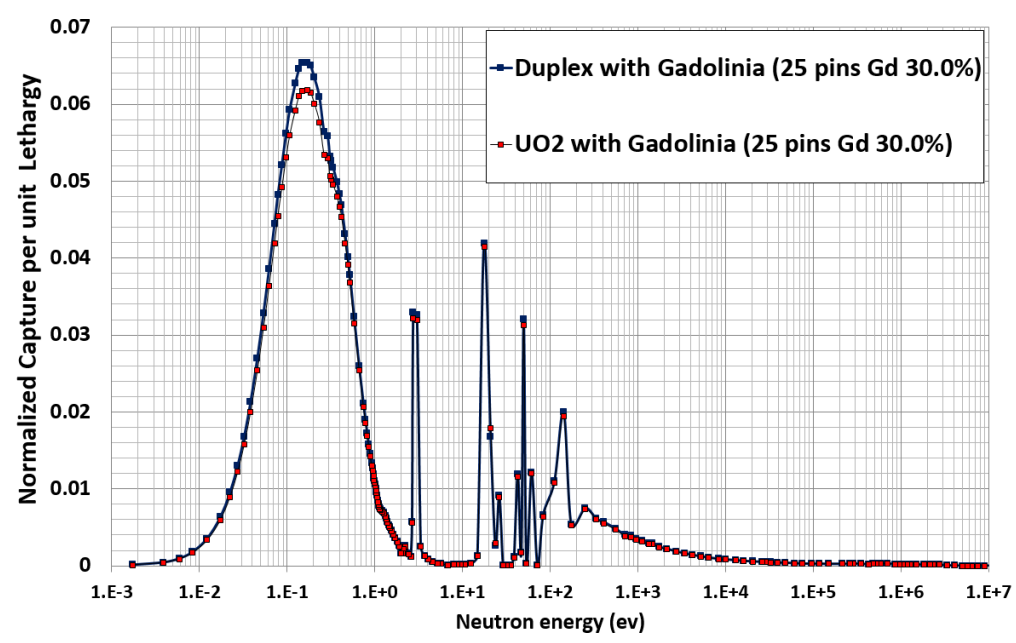

Fig. 13. Capture rates per unit lethargy with 25 absorber pins with $30 \% \mathrm{Gd}_{2} \mathrm{O}_{3}$ at $\mathrm{BOL}$

\subsubsection{Localized application of erbia}

Due to having a much lower cross-section than gadolinia, erbia $\left(\operatorname{Er}_{2} \mathrm{O}_{3}\right)$ is not consumed as quickly in a neutron flux (Franceschini and Petrović, 2009). As a result, erbia does not exhibit sharp shoulder points in $k_{\infty}$ vs. burnup graphs. Moreover, at the EOL, a larger amount of residual poison remains in the core, which necessarily shortens the core life. The effect of increasing the erbia concentration for the 17 and 25 pin cases is shown in Figs. 14a and $14 \mathrm{~b}$, respectively. The assembly reactivity decreases as the content of erbia increases, as expected. The residual reactivity penalty increases with higher $\operatorname{Er}_{2} \mathrm{O}_{3}$ content, and roughly doubles with twice the $\mathrm{Er}_{2} \mathrm{O}_{3}$ content.

Fig. 15 compares the reactivity swings for both candidate fuels for the 25 pins with $30 \%$ $\mathrm{Gd}_{2} \mathrm{O}_{3}$ and $30 \% \mathrm{Er}_{2} \mathrm{O}_{3}$ cases, and Fig. 16 shows the $k_{\infty}$ vs. burnup characteristics for the same cases. The burnup penalty arises from the residual poison that is not burned by EOL and the displacement of fissile material (replacing it with poison). Since erbia has a lower absorption cross-section, there is residual poison at EOL that leads to a burnup penalty. Due to the displacement of fissile material by BP, there is an inherent penalty which depends on the product of the number of pins and the concentration of poison. For a given effect on reactivity, gadolinia takes up less space due to its very high absorption cross-section and burns up faster than erbia, giving it a lower burnup penalty. In summary, it is evident that gadolinia is more effective than erbia as a BP in terms of all of reactivity swing, initial reactivity suppression and residual burnup penalty.

\subsubsection{Power peaking factor for localized poison application}

We have considered assembly-level power peaking factors (PPF) at BOL for $\mathrm{UO}_{2}$ and duplex assemblies with 25 absorber pins with $30 \% \mathrm{Gd}_{2} \mathrm{O}_{3}$ and $\mathrm{Er}_{2} \mathrm{O}_{3}$. One octant assemblies 


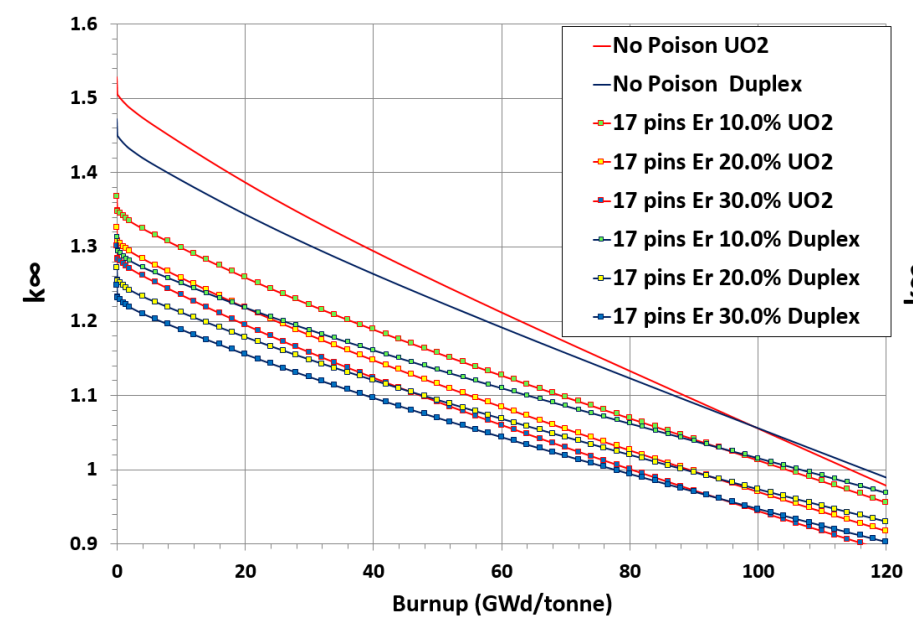

(a)

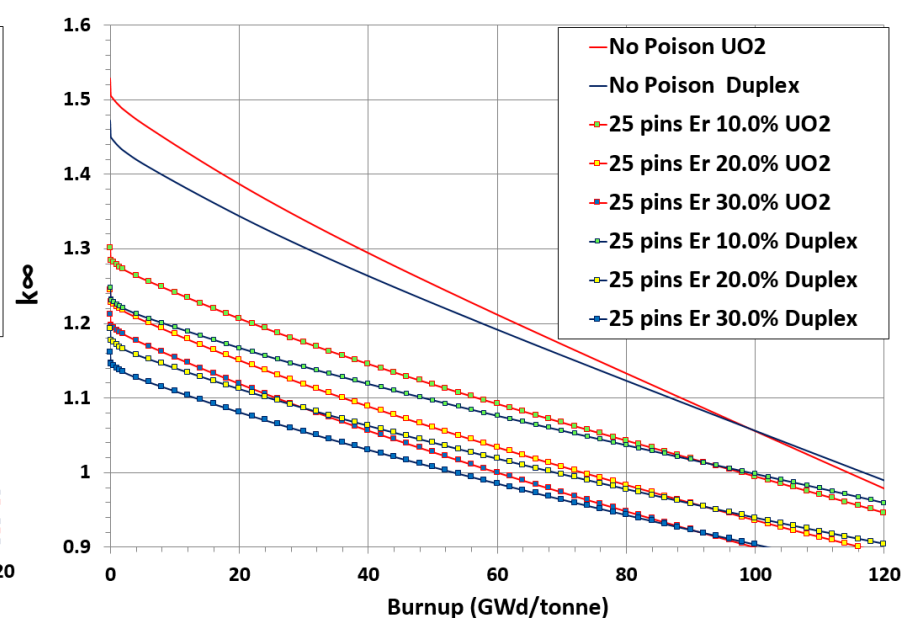

(b)

Fig. 14. $k_{\infty}$ vs. burnup for different $\mathrm{Er}_{2} \mathrm{O}_{3}$ concentrations: (a) $17 \mathrm{BP}$ pins; (b) $25 \mathrm{BP}$ pins.

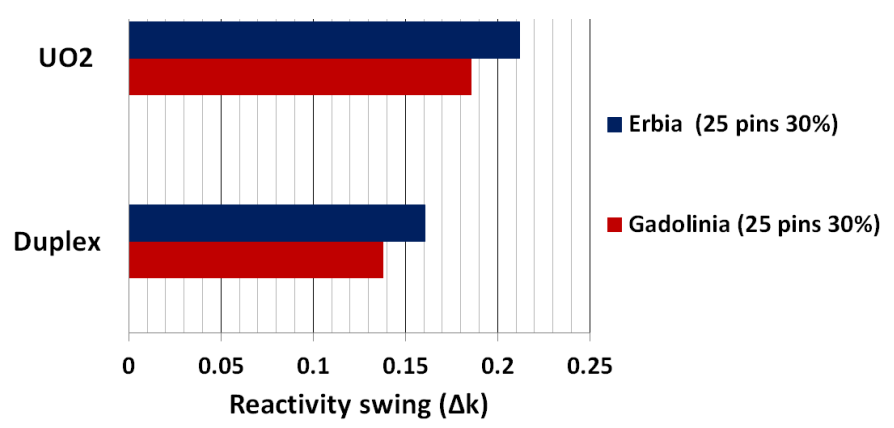

Fig. 15. Reactivity swing with $\mathrm{Gd}_{2} \mathrm{O}_{3}$ and $\mathrm{Er}_{2} \mathrm{O}_{3}$ for 25 absorber pins with a $30 \%$ concentration.

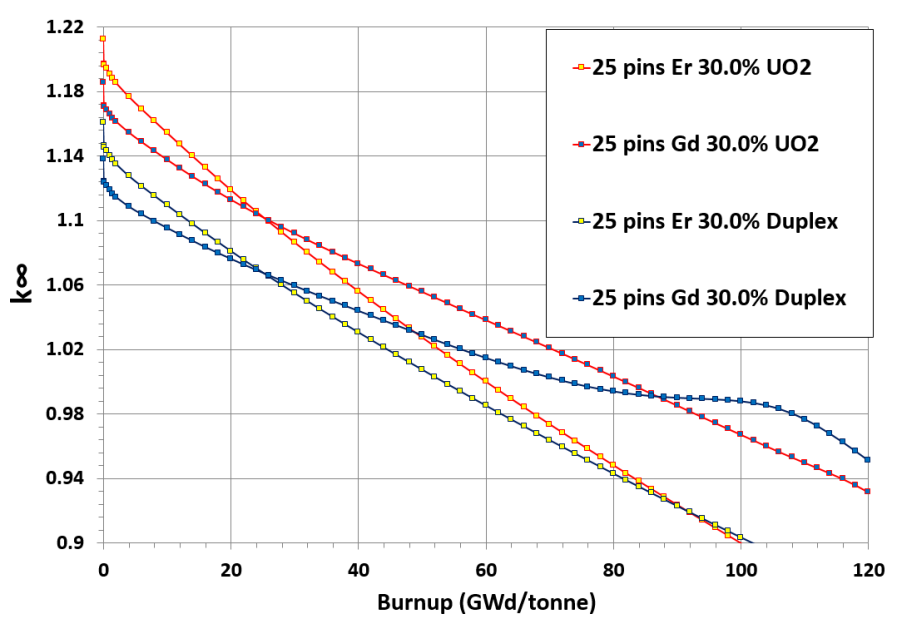

Fig. 16. $k_{\infty}$ vs. burnup for duplex and $\mathrm{UO}_{2}$ fuel with 25 absorber pins with $30 \% \mathrm{Gd}_{2} \mathrm{O}_{3}$ and $\operatorname{Er}_{2} \mathrm{O}_{3}$. 
are considered for performing PPF analysis. It can be seen for gadolinia (Fig. 17) and erbia (Fig. 18) that powers of fuel pins at the edge of the assembly (leftmost) are smaller than the centre of the assembly (rightmost) due to the softer spectrum arise from sufficient moderation (presence of water rods in the edge of the assembly). It can be observed in Fig. 17 that gadolinia-doped assemblies exhibit PPF of $\sim 1.29$ and $\sim 1.28$ with $\mathrm{UO}_{2}$ and duplex, respectively. On the contrary, Fig. 18 shows that the erbia-doped assemblies exhibit $\mathrm{PPF}$ of $\sim 1.26$ and $\sim 1.25$ with $\mathrm{UO}_{2}$ and duplex fuels, respectively. It is worthwhile noting that duplex assemblies contribute to $\sim 1-3 \%$ lower PPF than $\mathrm{UO}_{2}$, which is beneficial from the fuel performance perspective.

\begin{tabular}{|c|c|c|c|c|c|c|}
\hline & & & & \multicolumn{2}{|r|}{0.416} \\
\hline & & & & & 1.250 & 1.222 \\
\hline & & & & & 1.288 & \\
\hline & & & 1.134 & 1.166 & 1.199 & 1.232 \\
\hline & & & 1.101 & 0.398 & 1.126 & 1.190 \\
\hline & 1.060 & 1.073 & 1.042 & 1.023 & 1.125 & \\
\hline 1.098 & 1.038 & 0.381 & 0.967 & 0.383 & 1.087 & 1.166 \\
\hline
\end{tabular}

(a)

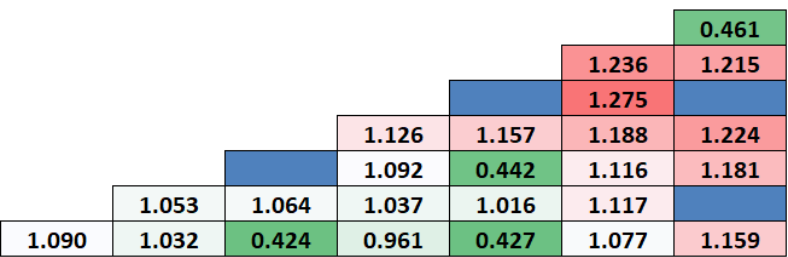

(b)

Fig. 17. Pin-by-pin power distribution at BOL with 25 absorber pins with $30 \% \mathrm{Gd}_{2} \mathrm{O}_{3}$. (a) $\mathrm{UO}_{2}$; (b) duplex fuels.

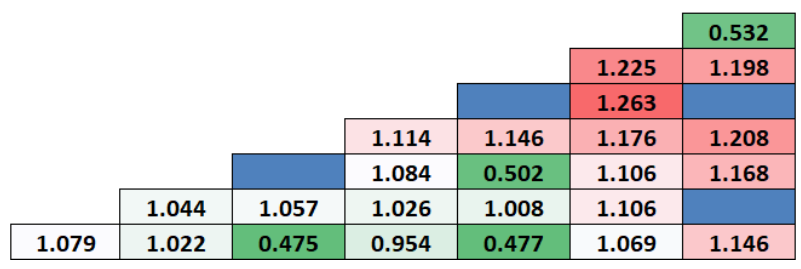

(a)

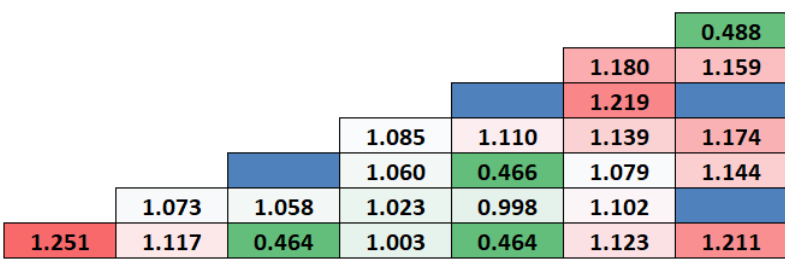

(b)

Fig. 18. Pin-by-pin power distribution at BOL with 25 absorber pins with $30 \% \mathrm{Er}_{2} \mathrm{O}_{3}$. (a) $\mathrm{UO}_{2}$; (b) duplex fuels.

\subsection{High-thickness coated neutron poison}

We have also considered IFBA designs adapted for duplex and $\mathrm{UO}_{2}$ fuels with 25 to 51 high-thickness IFBA rods in an assembly. For the duplex fuel case, IFBA layers are applied on the outer surface of the $\mathrm{ThO}_{2}$ region. It is clear from that the use of 25 pins with $30 \%$ $\mathrm{Gd}_{2} \mathrm{O}_{3}$ (Sect. 6.1.1) and $30 \% \mathrm{Er}_{2} \mathrm{O}_{3}$ (Sect. 6.1.2) exhibit a reactivity swing of $\sim 20,000 \mathrm{pcm}$ for the candidate fuels, which needs to be suppressed largely. In order to suppress this huge reactivity swing, we have considered higher loading of high-thickness IFBA rods (25 to 51 pins) than that of the $\mathrm{Gd}_{2} \mathrm{O}_{3}$ and $\mathrm{Er}_{2} \mathrm{O}_{3}$ in an assembly.

Many sources cite a standard thickness of $590 \mathrm{~nm}(1 \mathrm{~g} / \mathrm{cm})$ for a $\mathrm{ZrB}_{2}$ layer (Casadei and Esposito, 1990). In this study, we use boron $95 \%$ enriched in ${ }^{10} \mathrm{~B}$ throughout in order to increase neutronic effectiveness. Our previous study (Alam, 2018) showed that the 150 


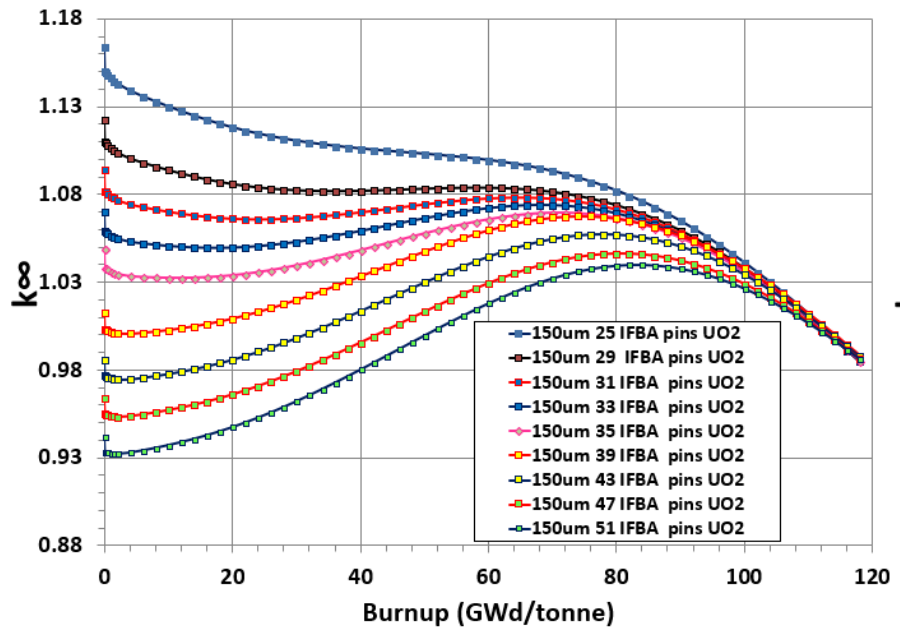

(a) coatings of $150 \mu \mathrm{m}$ only. increase the long term poison effectiveness.

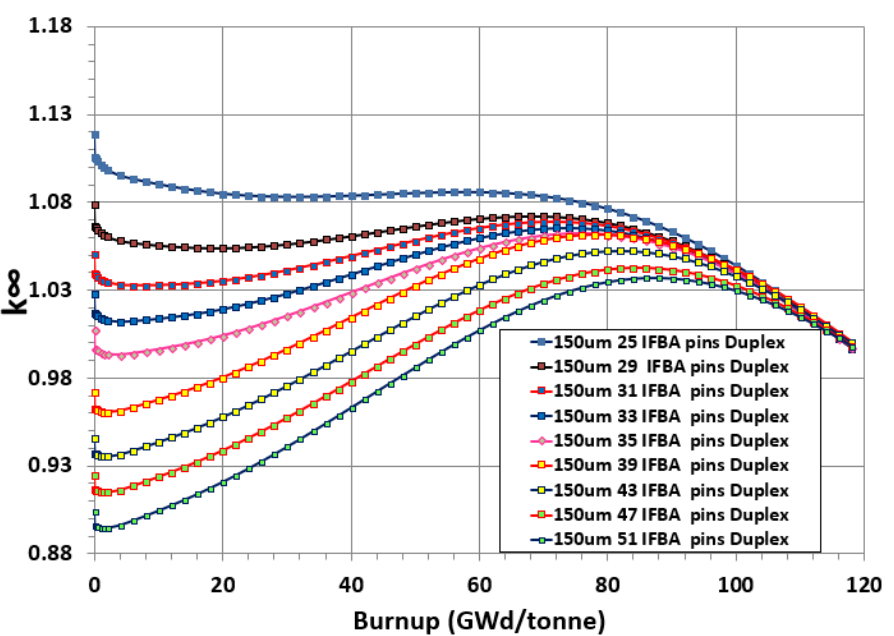

(b)

Fig. 19. $k_{\infty}$ vs. burnup for high-thickness $150 \mu \mathrm{m} \mathrm{ZrB} 2$ configurations: (a) $\mathrm{UO}_{2}$ fuel; (b) Duplex fuel.

$\mu \mathrm{m}$ thickness IFBA performs slightly better than $130 \mu \mathrm{m}$ in terms of reactivity swing, due to the stronger self-shielding effect in the thicker layer. Therefore, we have considered a high-thickness $\mathrm{ZrB}_{2}$ coating in order to achieve the crucial self-shielding effect, investigating

In boron $95 \%$ enriched with ${ }^{10} \mathrm{~B}$, the ratio of the absorption to total cross-section $\sigma_{a} / \sigma_{t}=0.95$, and therefore boron is an approximately black absorber. When incorporated into $\mathrm{ZrB}_{2}$ (density: $6.5 \mathrm{~g} / \mathrm{cm}^{3}$ ), it has a macroscopic absorption cross-section of $\Sigma=297$ $\mathrm{cm}^{-1}$, and therefore a mean free path $\lambda$ of $\sim 34 \mu \mathrm{m}$. As a result, $150 \mu \mathrm{m}$ coatings have poison layers with thicknesses greater than $4 \lambda$ and these high-thickness poison layers can therefore intercept at least $\sim 95 \%$ of incident neutrons. It is also worthwhile mentioning that according to a neutronic study conducted by LPSC, Universit Grenoble- Alpes, CNRS/IN2P3 (Alam, 2018), IFBA coating needs to have a mean free-path of $\lambda$ of $\sim 30 \mu \mathrm{m}$ and thickness would be between 70 and $150 \mu \mathrm{m}(2-4 \lambda)$ for ensuring long term depletion in a single batch core. Furthermore, to date, majority of the IFBA coatings are used in the cores with soluble boron system. It is evident by the previous studies (Otto, 2013, Fan, 2012) that if IFBA is used for the long life SBF marine core, thickness needs to be increased up to $200 \mu \mathrm{m}$ in order to

It can be observed in Figs. 19a and 19b that an increase in the number of high-thickness IFBA pins leads to higher poison longevity and lower reactivity swing for both the duplex and $\mathrm{UO}_{2}$ fuels. As the poison thickness increases the neutron flux within the fuel is significantly reduced, leading to a harder neutron spectrum. A harder spectrum favours the use of IFBA to reduce the reactivity swing (Alam, 2018, Alam et al., 2016e, Zainuddin et al., 2013). The IFBA designs also have negligible residual burnup penalty compared to gadolinia and erbia.

Fig. 20 compares the reactivity swings for both candidate fuels for the cases with 25 high-thickness $(150 \mu \mathrm{m})$ IFBA pins and 25 pins with $30 \% \mathrm{Gd}_{2} \mathrm{O}_{3}$, and Fig. 21 shows the 
$k_{\infty}$ vs. burnup characteristics for the same cases. It is apparent that the high-thickness IFBA design is more effective than the gadolinia design as a BP in terms of reactivity swing (Fig. 20) and initial reactivity suppression (Fig. 21) performance for both fuel cases. Although the absorption cross-section of gadolinia is higher than that of boron, IFBA provides $\sim 2 \%$ more initial reactivity suppression than gadolinia. This is due to the fact that gadolinia is mixed homogeneously with the fuel, which reduces the absorption effectiveness of the poison compared to the IFBA, which is coated onto the fuel and able to intercept $\sim 95 \%$ of the incident neutrons. The reactivity swing for IFBA is also $\sim 10 \%$ less than that for gadolinia. Since gadolinia is mixed uniformly with the fuel and therefore displaces fissile atoms, the fissile content of gadolinia-doped fuel changes faster than that of fuel with IFBA poison.

It is clear from Fig. 20 that for these BP designs, duplex fuel exhibits $\sim 25 \%$ less reactivity swing than $\mathrm{UO}_{2}$. The spatial separation between $\mathrm{ThO}_{2}$ and $\mathrm{UO}_{2}$ in duplex fuel facilitates improved absorption in ${ }^{232} \mathrm{Th}$, leading to efficient breeding of ${ }^{233} \mathrm{U}$. Fig. 21 also shows that duplex fuel outperforms $\mathrm{UO}_{2}$ by $\sim 4 \%$ in terms of BOL reactivity hold-down for the same thickness and number of IFBA pins. This is due to the lower initial reactivity of the unpoisoned duplex fuel, thanks to the higher neutron absorption cross-section of its fertile component $\left({ }^{232} \mathrm{Th}\right)$.

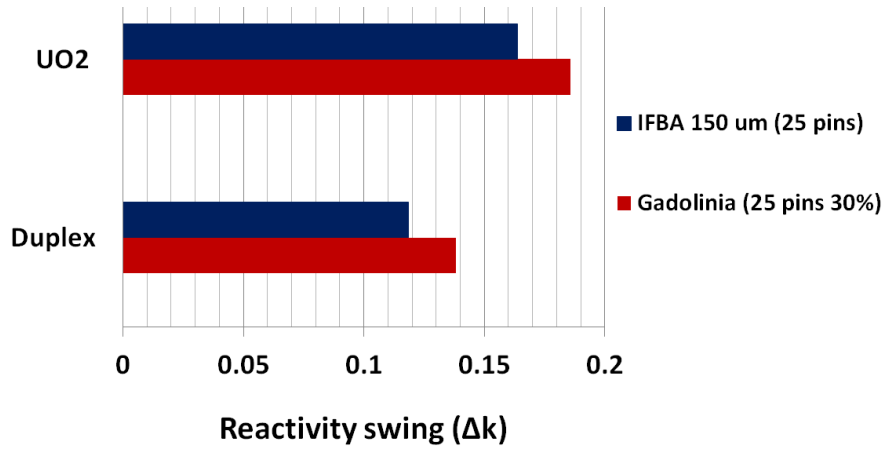

Fig. 20. Reactivity swing for duplex and $\mathrm{UO}_{2}$ fuel with gadolinia (25 pins with $30 \% \mathrm{Gd}_{2} \mathrm{O}_{3}$ ) and highthickness IFBA $(25 \times 150 \mu \mathrm{m}$ pins $)$.

It can be concluded that, even with IFBA poisons, the thorium-based duplex fuel outperforms $\mathrm{UO}_{2}$ in terms of initial reactivity and reactivity swing performance. Therefore, the number of poison pins required to achieve the same initial reactivity would be lower with duplex than $\mathrm{UO}_{2}$ fuel.

\subsection{Discussions on poison design}

Reactivity feedback coefficients are not evaluated in this assembly-level study, since we have performed detailed whole-core analyses in a companion paper (Alam et al., 2019c). From our BP study, it can be observed that high-thickness IFBA is more effective than gadolinia as a BP in terms of reactivity swing, initial reactivity suppression and residual burnup penalty performance for both candidate fuels. $\mathrm{ZrB}_{2}$ IFBA with enriched boron outperforms $\mathrm{Gd}_{2} \mathrm{O}_{3}$ due to the fact that a poison layer with a thickness of $3 \lambda$ absorbs $\sim 95 \%$ of incident neutrons. 


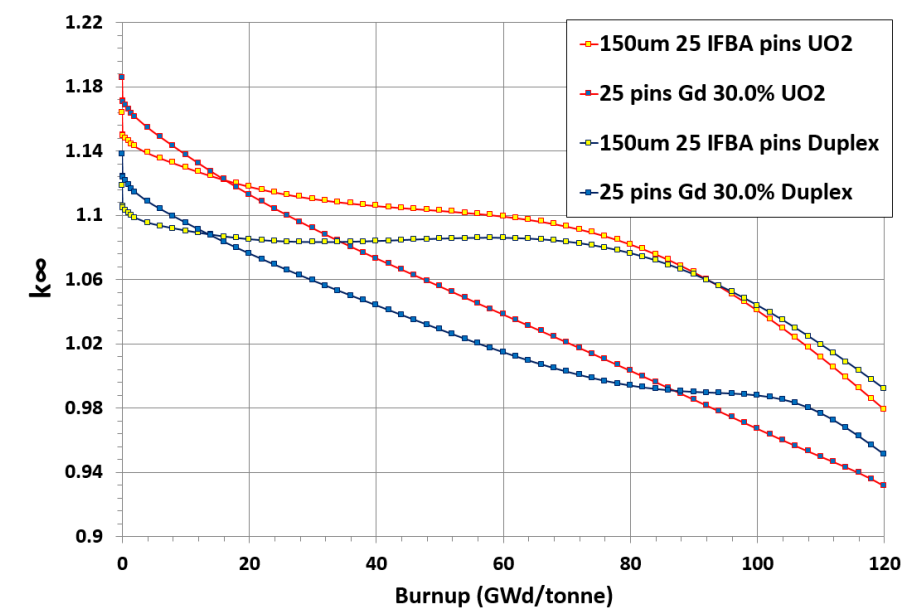

Fig. 21. $k_{\infty}$ vs. burnup for duplex and $\mathrm{UO}_{2}$ fuel with gadolinia (25 pins with $30 \% \mathrm{Gd}_{2} \mathrm{O}_{3}$ ) and high-thickness IFBA $(25 \times 150 \mu \mathrm{m}$ pins $)$.

This is a great improvement over the $\mathrm{Gd}_{2} \mathrm{O}_{3}$ and $\mathrm{Er}_{2} \mathrm{O}_{3}$ poison cases, some of which had a significant EOL burnup penalty.

It is worth noting that, in allowing for the effect of neutron leakage, we have considered higher BOL reactivity (only 33 IFBA pins) in this assembly-level analysis: a small core might exhibit more leakage than anticipated in the design method (as discussed in Sect. 3.3). We consider a higher reactivity swing limit of 5000-7000 pcm in this assembly-level analyses since neutron leakage isn't considered in WIMS code. It is worth addressing that our target is to keep the through-life reactivity swing below $4000 \mathrm{pcm}$ in the whole-core level. It is seen that 33 IFBA pins exhibit a reactivity swing of $6000 \mathrm{pcm}$. Since an increase in the BP loading ( $>33 \mathrm{BP}$ pins) in lattice levels lead to subcriticality, it is recommended not to use more than 33 BPs for the candidate fuels in this assembly-level calculation.

Early in life, the fuel in these pins sees only a severely attenuated neutron flux and is gradually brought up to power as the poison burns out. This results in a power-sharing arrangement: the pins that were coated in poison have higher fissile content and power late in life. Therefore, it is required to observe the BOL power peaking factors for this 33 pins high thickness IFBA. We have considered assembly-level power peaking factors (PPF) at BOL for $\mathrm{UO}_{2}$ and duplex assemblies with 33 absorber pins for IFBA. In order to assure that through-life pin-level power peaking doesn't exceed the allowable limit, middle-of-life (MOL) and EOL peaking are also considered for 33 IFBA pins. One octant assemblies are considered for performing PPF analysis. Similar to the findings of gadolinia and erbia, it can be seen from Figs. 22 and 23 for IFBA that powers of fuel pins at the edge of the assembly (leftmost) are smaller than the centre of the assembly (rightmost). It can be observed that $\mathrm{UO}_{2}$ and duplex assemblies exhibit BOL PPF of $\sim 1.28$. As expected, the highest pin peaking occurs at BOL; and MOL and EOL PPF are 9\% lower than BOL PPF for both the candidate fuels. The largest radial PPF in the assembly-level for the candidate fuels are smaller than that of the limiting value of 1.5 (Pramuditya and Takahashi, 2013), which can assure the safety. 


\begin{tabular}{|c|c|c|c|c|c|c|}
\hline & & & & \multicolumn{2}{|r|}{0.628} \\
\hline & & & & & 1.260 & \\
\hline & & & & & 1.280 & \\
\hline & & & 1.153 & 1.178 & 1.159 & 0.652 \\
\hline & & & 1.121 & 0.622 & 1.113 & 1.152 \\
\hline & 1.017 & 1.068 & 1.054 & 1.028 & 1.143 & \\
\hline 0.553 & 0.929 & 0.576 & 0.958 & 0.593 & 1.116 & 1.204 \\
\hline
\end{tabular}

(a)

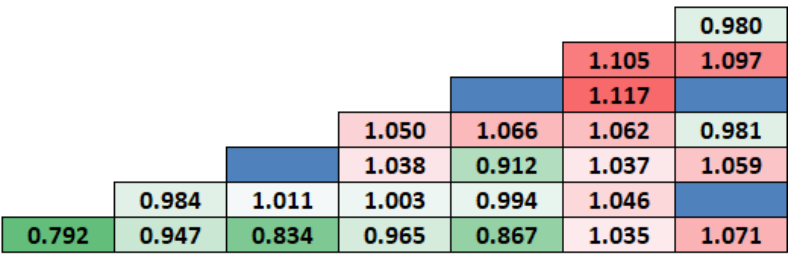

(b)

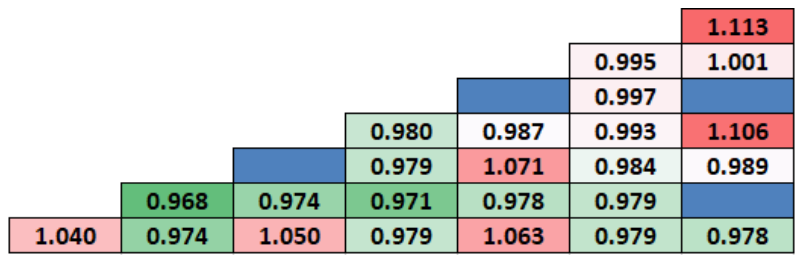

(c)

Fig. 22. Pin-by-pin power distribution for $\mathrm{UO}_{2}$ fuel with 33 absorber pins with $150 \mu \mathrm{m}$ IFBA pins. (a) BOL; (b) MOL; (c) EOL.

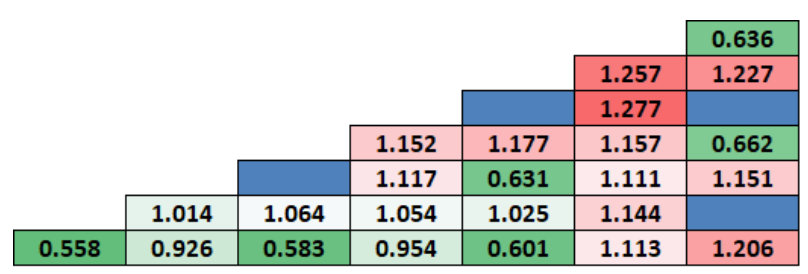

(a)

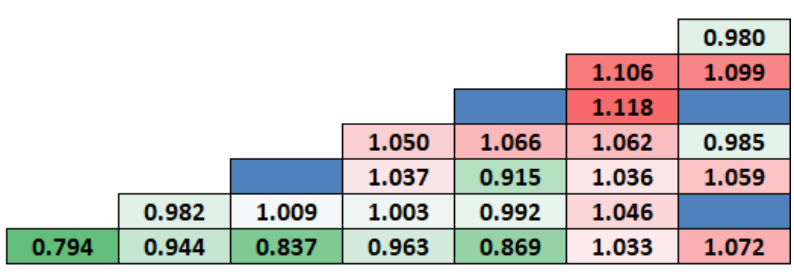

(b)

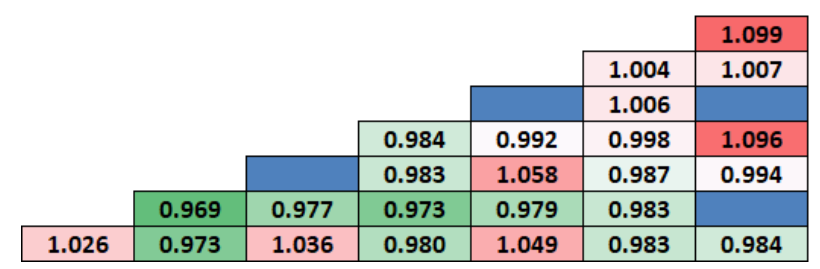

(c)

Fig. 23. Pin-by-pin power distribution for duplex fuel with 33 absorber pins with $150 \mu \mathrm{m}$ IFBA pins. (a) BOL; (b) MOL; (c) EOL. 
For both duplex and $\mathrm{UO}_{2}$ fuels, the successful $\mathrm{BP}$ design used 33 pins poisoned with a $150 \mu \mathrm{m}$ thick layer of $\mathrm{ZrB}_{2}$ since further increase in the number of IFBA pins $(>33 \mathrm{BP}$ pins) lead to the subcriticality. Therefore, this poison design will be used in our control rod analysis in the next section.

If the whole-core analysis (Alam et al., 2019c) shows that the initial reactivity is too high, more IFBA pins can be used to hold down reactivity at BOL. Since an assembly-level study can't consider the effect of neutron leakage, there is no way to finalize the poison loading for the whole-core. In addition, the objective of this study was not to perform the assembly-level BP optimization. The idea was to understand the poison requirement from the lattice-level study. Most importantly, if the whole-core analysis exhibits higher initial reactivity than the anticipated, more IFBA pins will be employe in the whole-core level (Alam et al., 2019c) through the proper section for satisfying the safety criterion. It is worthwhile addressing that poisons are selected in such a way that there is no problem in satisfying the peaking factors (radial, axial, etc.) and higher local burnup values in the lattice and the whole-core level (Alam et al., 2019c). The use of IFBA pins can make the power peaking factors situation worse because of the high pin power peaks in non-IFBA fuel pins. The highest PPF is lower than that of highest PPF limit of 1.50, so the safety can be guaranteed. The choice of IFBA pins is set in the whole-core analysis in such a way that the addressed problem has been avoided. From a fuel manufacturing perspective, while the use of IFBA burnable absorber in $\mathrm{UO}_{2}$ fuel is a consolidated practice in Westinghouse, its viability for the duplex rods needs to be confirmed in future studies.

\section{Control rod design}

Using 33 pins coated with a $150 \mu \mathrm{m}$ layer of $\mathrm{ZrB}_{2}$ poison, we have seen in Sect. 6 that in full-power operation $k_{\infty}($ duplex $)<1.119\left(\rho_{\text {duplex }}<0.107\right)$ and $k_{\infty}\left(\mathrm{UO}_{2}\right)<1.164$ $\left(\rho_{\mathrm{UO}_{2}}<0.141\right)$ throughout the entire core lifetime. We aim for a shutdown margin of $\rho_{\mathrm{SM}} \geq 0.14$ at any point in life (Otto, 2013, Alam, 2018). To determine the necessary control rod worth, we must first evaluate the core's reactivity in a variety of temperature and power conditions. Then we must determine how many control rods and what control materials are necessary to satisfy the shutdown margin requirement.

\subsection{Assembly reactivity in different temperature and power conditions}

In an under-moderated reactor, decreasing the moderator temperature leads to a betterthermalized neutron spectrum, lower resonance absorption in the fuel, and hence higher reactivity. Similarly, lower fuel temperatures lead to a narrowing of the epithermal resonances in the fuel, increased resonance escape probability and higher reactivity. Thus, during times of lower fuel or moderator temperatures, the core will have higher reactivity than in its standard operating state. When determining the optimal control rod worth, it is essential that there is enough reactivity for a quick shutdown even in these cold or low-power conditions. To evaluate these various scenarios, the assembly reactivity is measured in three temperature/power conditions: Standard operation (hot full power (HFP)), hot zero power (HZP) and cold critical (cold zero power (CZP)). These conditions are defined in Table 3. 


\begin{tabular}{|l|c|c|c|}
\hline Condition & Fuel temperature $(\mathrm{K})$ & Coolant temperature $(\mathrm{K})$ & Coolant density $\left(\mathrm{kg} \mathrm{m}^{-3}\right)$ \\
\hline HFP & 900 & 580 & 707 \\
HZP & 580 & 580 & 707 \\
CZP & 295 & 295 & 1005 \\
\hline
\end{tabular}

Table 3. Different temperature and power conditions.

Fig. 24 shows the variation in assembly reactivity with burnup at these three conditions for both the duplex and $\mathrm{UO}_{2}$ fuels.

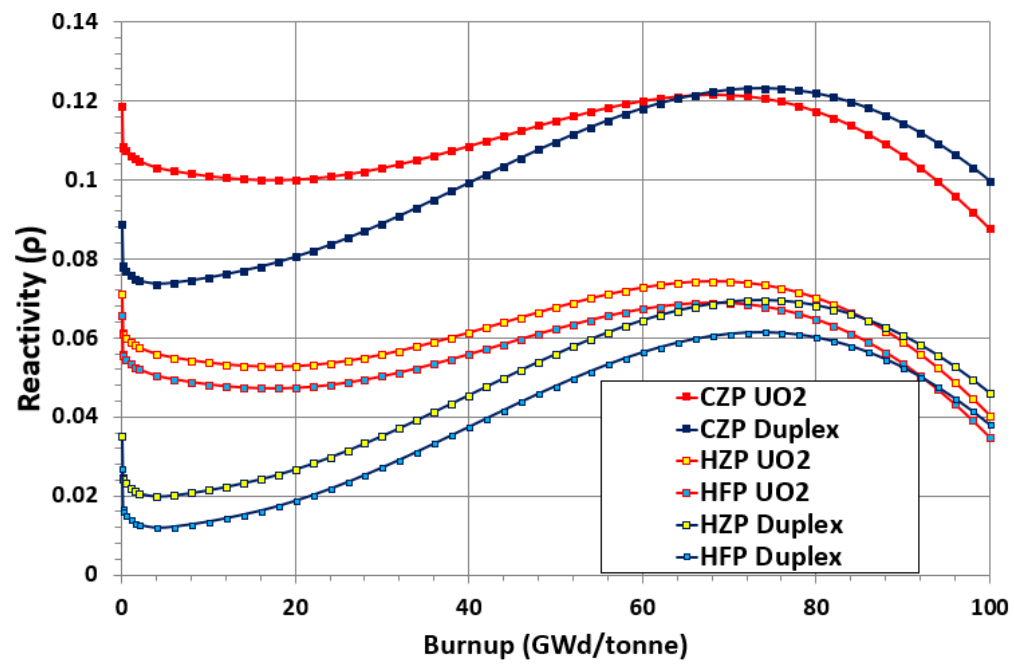

Fig. 24. Assembly reactivity variation with burnup in different conditions for both fuels.

Reviewing Fig. 24, we note that the maximum lifetime reactivity of the assembly in its cold-critical state is $\rho_{\max }($ duplex $)=0.123$ and $\rho_{\max }\left(\mathrm{UO}_{2}\right)=0.122$. With our desired shutdown margin $\rho_{\mathrm{SM}}$ of 0.14 , the control rods must therefore have a reactivity worth of $\rho_{\mathrm{CR}}($ duplex $)=0.263$ and $\rho_{\mathrm{CR}}\left(\mathrm{UO}_{2}\right)=0.262$.

\subsection{Candidate control rod materials}

Candidate control materials for our SBF marine core should have a high capture crosssection, be compatible with other core materials within operating temperatures and pressures and resistant to radiation damage. PWRs for power generation use boron carbide $\left(\mathrm{B}_{4} \mathrm{C}\right)$, hafnium (Hf), gadolinium (Gd), cadmium (Cd) and an alloy of Ag- $80 \%$ In-15\% Cd-5\% (AIC) as control rod materials.

From a reactor physics standpoint, the choice of control rod material is influenced by the neutron spectrum in the core since some control materials have high capture cross-sections only in specific energy ranges. The capture cross-sections of boron and Hf are large over a considerable range of neutron energies, making them suitable not only as control materials but also for neutron shielding. Each element in the AIC alloy has a significant capture cross-section in a certain energy range and the combination of elements covers the whole energy spectrum (Shaposhnik et al., 2014). In contrast, Gd and Cd exhibit high capture 
cross-sections only in the thermal energy range (Shaposhnik et al., 2014). We therefore examine $\mathrm{B}_{4} \mathrm{C}$, $\mathrm{Hf}$ and $\mathrm{AIC}$ as candidate control rod materials for our marine core.

\subsection{Rod cluster control assembly worth}

The existing subassembly design has 16 guide-tubes for loading control rods (Fig. 1a). Therefore, for each material, we evaluate the BOL worth $(\Delta \rho)$ of a 16-rod rod cluster control assembly (RCCA) at full insertion. The results are shown in Table 4.

\begin{tabular}{|l|c|c|}
\hline Material & $\Delta \rho\left(\mathrm{UO}_{2}\right)$ & $\Delta \rho($ duplex $)$ \\
\hline $\mathrm{Hf}$ & 0.208 & 0.216 \\
$\mathrm{~B}_{4} \mathrm{C}$ & 0.353 & 0.369 \\
$\mathrm{AIC}$ & 0.200 & 0.207 \\
\hline
\end{tabular}

Table 4. RCCA (16-rod) worth for various rod materials.

It can be seen that the RCCA worth $\Delta \rho$ is $\sim 5 \%$ higher for the duplex fuel than $\mathrm{UO}_{2}$ for all control materials. This is due to the harder spectrum experienced by the $\mathrm{UO}_{2}$ fuel (see Fig. 7) (Fridman and Kliem, 2011). It is also clear that the worth of the $\mathrm{B}_{4} \mathrm{C}$ rods is substantially greater for both fuels, due to the higher normalized capture per unit lethargy (Fig. 25), making it the natural choice of control rod material to take forward in this study.

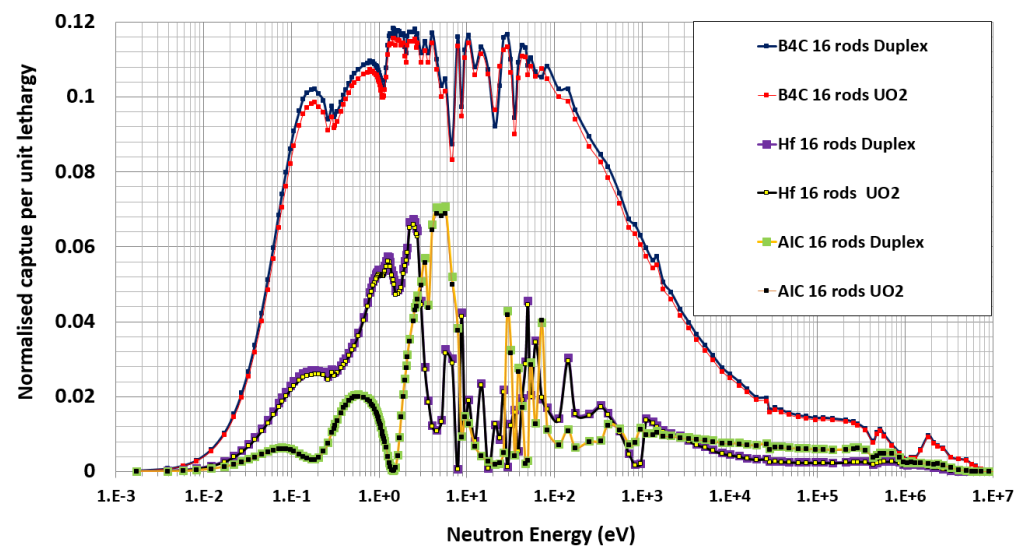

Fig. 25. Normalized capture per unit lethargy at BOL for 16 control rods.

The differences in normalized capture per unit lethargy between duplex and $\mathrm{UO}_{2}$ fuels at BOL for 16 control rods of each type are evaluated in Fig. 26. This confirms that the greater RCCA worth in the duplex fuel is due to higher capture rates at lower neutron energies for all the candidate materials.

\subsection{Number of control rods in $R C C A$}

Since we have chosen $\mathrm{B}_{4} \mathrm{C}$ as our control material, we can see from Table 4 that the worths of our RCCA, $\Delta \rho$ (duplex $)=0.369$ and $\Delta \rho\left(\mathrm{UO}_{2}\right)=0.353$, are greater than the minimum required worths calculated in Sect. 7.1: $\rho_{\mathrm{CR}}($ duplex $)=0.263$ and $\rho_{\mathrm{CR}}\left(\mathrm{UO}_{2}\right)=0.262$. It might therefore be possible to reduce the number of control rods in the RCCA. If the 


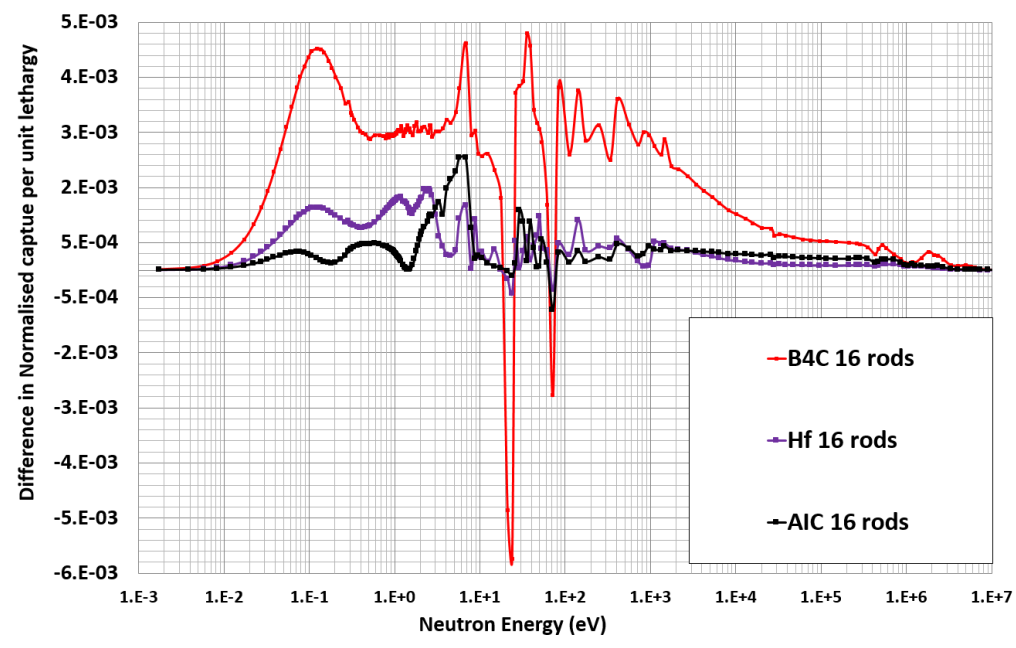

Fig. 26. Differences in normalized capture per unit lethargy between duplex and $\mathrm{UO}_{2}$ fuels at $\mathrm{BOL}$ for 16 control rods.

guide tubes were replaced with fuel pins, this would allow the reactor to operate with lower enrichment fuel and might well also reduce power peaking. However, if octant symmetry is to be maintained, which has been cited as an essential feature for subassembly design (Haibach and Feltus, 1997), then a minimum of 4 rods must be removed. Our investigations show that the required shutdown margin cannot be achieved for either fuel with only $12 \mathrm{~B}_{4} \mathrm{C}$ control rods in the RCCA. A standard 16-rod RCCA will therefore be used in subsequent studies.

\section{Reactivity Feedback Coefficients}

Our control rod design incorporated 33 pins coated with a $150 \mu \mathrm{m}$ layer of $\mathrm{ZrB}_{2}$ poison for both duplex and $\mathrm{UO}_{2}$ fuels. In this section, assembly-level reactivity coefficients moderator temperature coefficient (MTC) and fuel temperature coefficient (FTC) are evaluated at HFP conditions. FTC values are evaluated by increasing the fuel temperature by $20 \mathrm{~K}$ from the reference value of $900 \mathrm{~K}$. MTC values are calculated by increasing the coolant temperature by $20 \mathrm{~K}$ and modifying the water density accordingly.

Fig. 27 shows that the values of FTC are negative thorough-life for both fuels. The FTC of the duplex fuel is considerably more negative compared to the $\mathrm{UO}_{2}$ fuels due to the stronger Doppler effect of Th-232 that arises from increased Doppler broadening by the simultaneous presence of ${ }^{232} \mathrm{Th}$ and ${ }^{238} \mathrm{U}$ (Baldova et al., 2014, Björk et al., 2011).

Fig. 28 shows that MTC is more negative in the duplex fuel compared to $\mathrm{UO}_{2}$ fuel at BOL due to the increased neutron absorption in the ${ }^{232} \mathrm{Th}$ resonances as the moderator temperature increases (Lau et al., 2012). The MTC is higher at BOL for both fuels, and the MTC decreases with burnup due to the changes in isotopic composition and increased variety of isotopes. On the other hand, MTC is slightly more negative in the $\mathrm{UO}_{2}$ than duplex at EOL. As the burnup progresses, more plutonium is generated for $\mathrm{UO}_{2}$ fuel compared to duplex (Liu and Cai, 2014). Due to the strong thermal neutron absorption of plutonium, MTC is more negative in $\mathrm{UO}_{2}$ than duplex fuel at EOC. 


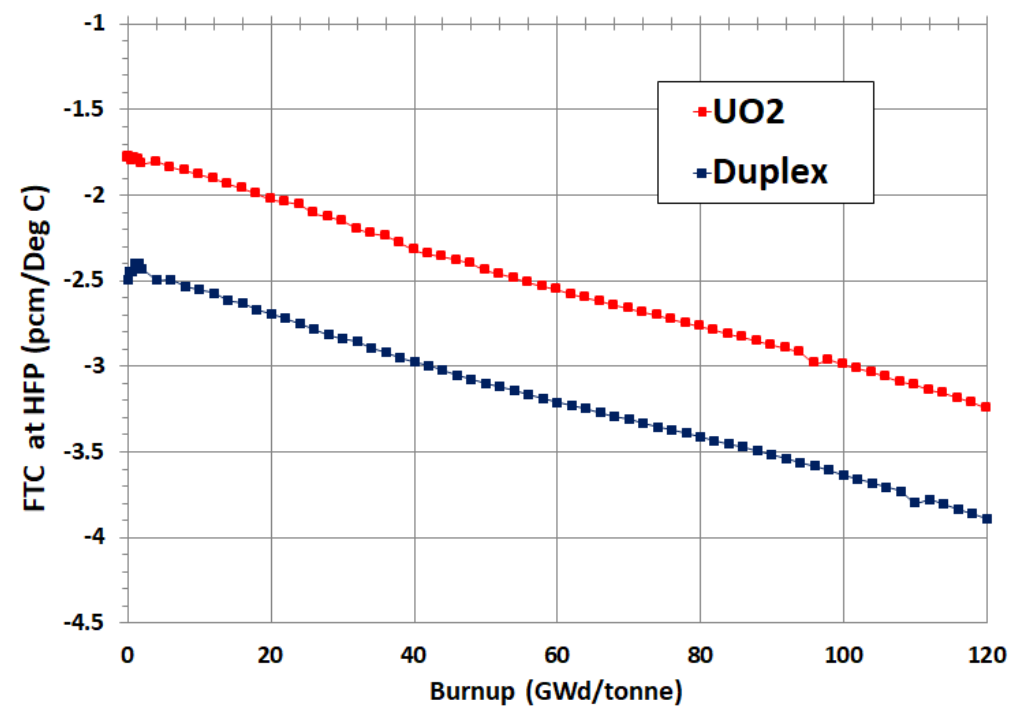

Fig. 27. FTC over burnup with 33 pins coated in a $150 \mu m$ layer of $Z r B_{2}$ poison.

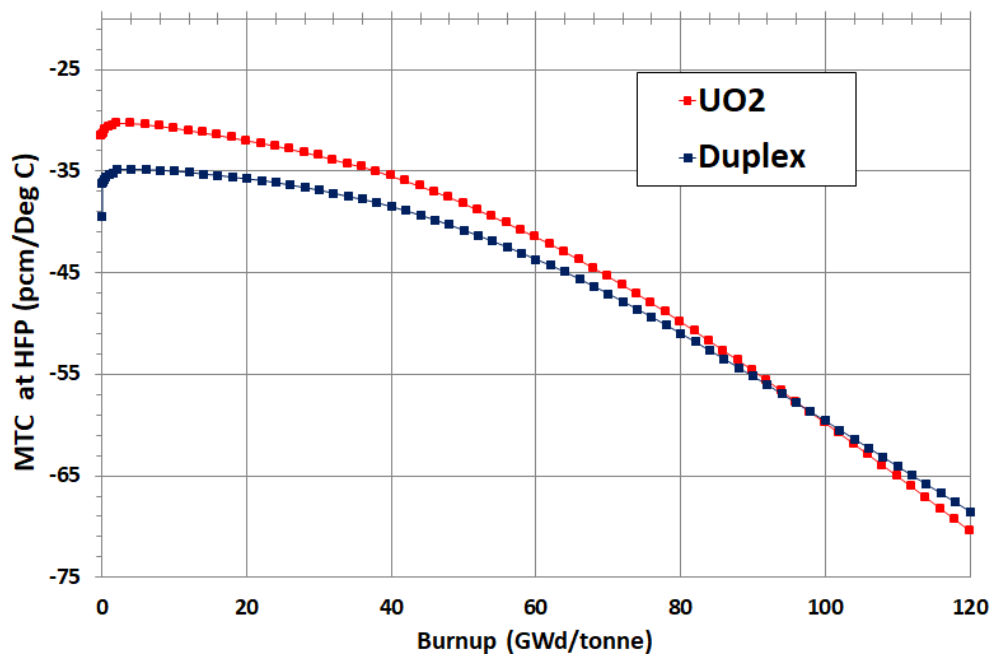

Fig. 28. MTC over burnup with 33 pins coated in a $150 \mu m$ layer of $Z r B_{2}$ poison. 


\section{Practical considerations for the duplex fuel}

The major challenge for the micro-heterogeneous duplex fuel arrangements is to meet the thermal-hydraulic margins since the most severe situation will be in the duplex pellet case where most of the power is generated in the $\mathrm{UO}_{2}$ part of the fuel pellet. In order to confirm that all the thermal-hydraulic constraints are satisfied for the duplex fuel, 3D neutronic/thermal-hydraulic coupling of hybrid monte carlo MONK with sub-channel analysis COBRA-EN (Basile, 1999) code for hot channel analysis (Alam et al., 2019d) has been performed to evaluate key TH parameters such as: minimum departure from nucleate boiling ratio (MDNBR), heat flux, cladding, inner surface and fuel centreline temperatures, and pressure drop. Our study confirmed that thermal-hydraulic design requirements for the duplex fuel can be met and there will be no melting in the $\mathrm{UO}_{2}$ region of the duplex pellet. Since thermal-hydraulic design requirements are met by a good margin, it can, therefore, be expected that other issues (e.g. hydriding of cladding, fission gas release, and pellet/cladding mechanical interactions) arising from the large temperature gradients in the $\mathrm{UO}_{2}$ part of the fuel pellet can be avoided. These issues are out of the scope of this paper and detailed hot channel thermal-hydraulic analysis can be found in the first author's PhD research (Alam, 2018).

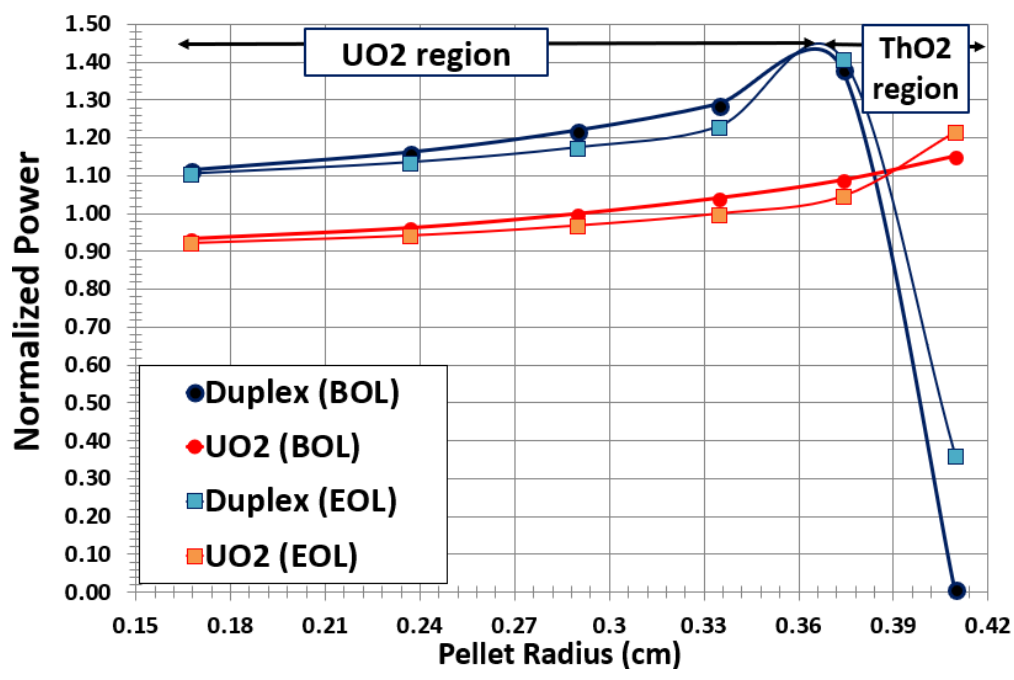

Fig. 29. Normalized power density distribution for duplex fuel (at the $\mathrm{UO}_{2}-\mathrm{ThO}_{2}$ interface) and all-UO fuel.

The power peaking problem is also observed for the duplex fuel for the $\mathrm{Zr}$ case plotted as a function of normalized power along the duplex pellet radius at BOL. Fig. 29 shows that normalized power of duplex pellet (at the $\mathrm{UO}_{2}-\mathrm{ThO}_{2}$ interface) is about a factor of 1.4 at the BOL and almost $20 \%$ higher than the all- $\mathrm{UO}_{2}$ fuel. It is clear that power peaking can be kept below standard industry limit of 1.5 (Pramuditya and Takahashi, 2013). It is worthwhile mentioning that previous studies (Alam, 2018, Shwageraus et al., 2004) exhibit a normalized power of 2.4 for axially micro-heterogeneous duplex fuel and this higher BOL normalized power $\mathrm{UO}_{2}$ region results in an unacceptably high fuel temperature. In order to 
avoid this issue, our radial micro-heterogeneous duplex fuel is designed in such a way that $\mathrm{ThO}_{2}$ region is $\sim 25 \%$ of the $\mathrm{UO}_{2}$ region and normalized power is limited to 1.4 , which is an obvious design improvement considering the practical perspective. A detailed discussion of the radial micro-heterogeneous duplex fuel design and analyses can be found in the first author's PhD research (Alam, 2018).

The outer $\mathrm{ThO}_{2}$ layer in the duplex fuel might results in the burnup and power gradients and can also degrade the irradiation performances. Fuel performance issues for the duplex fuel are worth investigating the future. It is also worth addressing that the main objective of this paper is to evaluate the neutronic feasibility of the duplex fuel in a SBF environment. We have considered the issues of the associated complexities (peak temperatures, local burnup) of duplex fuel in the previous study (Alam, 2018) and these issues are, however, out of the scope of this paper since it is limited to the neutronic study of assembly-level.

In combination with a new fuel type (i.e. duplex Th-U pellet) for prototype SMR for civil nuclear marine propulsion, the authors didn't consider the licensing/manufacturing point of view since this study was a complete neutronic feasibility of an alternative fuel platform.

\section{Conclusions}

This paper demonstrates the superiority of duplex fuel in terms of neutronic characteristics than that of the traditional $\mathrm{UO}_{2}$ fuel. It is indeed a strong motivation to understand the underlying physics of the duplex fuel core and observe the neutronic performance of the proposed duplex core with respect to the $\mathrm{UO}_{2}$ fuel. The idea of this paper is not just to obtain the satisfactory neutronic performance, but to successfully "open the option" of designing the proposed SBF, marine SMR core with both the duplex and $\mathrm{UO}_{2}$ fuel cores. The main objectives of this paper are to investigate and understand the behaviour of the candidate burnable poisons and control rods in a long-life, SBF environment for a PWR marine SMR core, and most importantly compare the performance of the candidate thorium-based duplex and all-uranium fuels. Furthermore, in this study, higher local burnup is not considered as a constraint (or limiting factor as with current commercial reactors) for the design of long life core, instead, it is an objective. For the purpose of this study, it is assumed that suitable materials and technology that can withstand prolonged core life and high burnup will be available for future use for the long life marine core. The main findings of this paper are:

- It is seen that gadolinia gives a small EOL residual penalty while high-thickness IFBA gives a relatively small/negligible EOL residual. In contrast, erbia has a relatively large EOL residual.

- As far as the reactivity swing and BOL reactivity suppression are concerned, highthickness IFBA is a better choice than gadolinia.

- The duplex fuel has a lower initial reactivity and smaller reactivity swing than the uranium-only alternative, reducing the burnable poison requirements. 
- The worth of $\mathrm{B}_{4} \mathrm{C}$ rods is substantially greater than the alternative control materials considered for both fuels, making it the natural choice of control rod material to take forward in this study.

- Control rods have greater worth in a duplex core than $\mathrm{UO}_{2}$, reducing the control material requirements and thus potentially the cost of the rods.

- MTC and FTC values are observed to be more negative in the duplex fuel than the $\mathrm{UO}_{2}$ fuel.

In order to assess the effects of neutron leakage and spatial flux dependence, whole-core analyses are discussed in a companion paper (Alam et al., 2019c).

We have considered the issues of the associated complexities (peak temperatures, local burnup) of duplex fuel in the previous study (Alam, 2018) and these issues are, however, out of the scope of this paper since the scope of these papers are limited to the neutronic study of assembly-level. Future works will focus on the following aspects:

- One of the important safety aspects is fuel performance issues which needs to be investigated in the future. It is recommended that fuel performance analyses for the proposed high burnup core be undertaken to verify the integrity of the fuel rods including Integral fuel rod performances and fission gas release (FGR), pellet-clad interaction (PCI) phenomena caused by excessively high rod internal gases and pellet swelling; and oxide thickness (corrosion).

- From a fuel manufacturing perspective, while the use of IFBA burnable absorber in $\mathrm{UO}_{2}$ fuel is a consolidated practice in Westinghouse, its viability for the duplex rods needs to be confirmed in future studies.

- Since power density is an important figure of merit and characterizes design performance, future work will focus on the neutronics and coupled neutronic/thermal-hydraulic analysis of high power density marine SMR candidate core designs.

\section{References}

Alam, S.B., 2018. The Design of Reactor Cores for Civil Nuclear Marine Propulsion. Ph.D. thesis. University of Cambridge.

Alam, S.B., Almutairi, B., Goodwin, C.S., 2018a. Neutronic assessment of accident-tolerant cladding concepts for civil nuclear marine propulsion cores. Part I: Reactivity \& spectral hardening, in: Proc. PHYSOR 2018, Cancun, Mexico. pp. 3142-3153.

Alam, S.B., Almutairi, B., Goodwin, C.S., 2018b. Neutronic assessment of accident-tolerant cladding concepts for civil nuclear marine propulsion cores. Part II: Rim effect \& reactivity feedback analysis, in: Proc. PHYSOR 2018, Cancun, Mexico. pp. 3154-3165.

Alam, S.B., Goodwin, C., Parks, G.T., 2017a. Reactor physics assessment of candidate accident-tolerant cladding concepts for long-life civil nuclear marine propulsion cores, in: Proc. ICAPP 2017, Fukui and Kyoto, Japan. pp. 17309-17318. 
Alam, S.B., Goodwin, C.S., Parks, G.T., 2019a. Assembly-level analyses of accident-tolerant cladding concepts for a long-life civil marine SMR core using micro-heterogeneous duplex fuel. Progress in Nuclear Energy 111, 24-41.

Alam, S.B., Goodwin, C.S., Parks, G.T., 2019b. Parametric neutronics analyses of lattice geometry and coolant candidates for a soluble-boron-free civil marine SMR core using micro-heterogeneous duplex fuel. Annals of Nuclear Energy 129, 1-12.

Alam, S.B., Kumar, D., Almutairi, B., Bhowmik, P.K., Goodwin, C., Parks, G.T., 2019c. Small modular reactor core design for civil marine propulsion using micro-heterogeneous duplex fuel. Part II: Whole-core analysis. Nucl Eng Des. submitted.

Alam, S.B., Lindley, B.A., Parks, G.T., 2015. Feasibility study of the design of homogeneously mixed thorium-uranium oxide and all-uranium fueled reactor cores for civil nuclear marine propulsion, in: Proc. ICAPP 2015, Nice, France. pp. 1918-1927.

Alam, S.B., Lindley, B.A., Parks, G.T., 2016a. Hot channel analysis of a 333 MWth civil nuclear marine core using the COBRA-EN code, in: Proc. 16th International Topical Meeting on Nuclear Reactor Thermal Hydraulics (NURETH-16), Chicago, Illinois, USA. pp. 5900-5913.

Alam, S.B., Lindley, B.A., Parks, G.T., 2016b. Neutronic performance of high power density marine propulsion cores using $\mathrm{UO}_{2}$ and microheterogeneous $\mathrm{ThO}_{2}-\mathrm{UO}_{2}$ duplex fuels, in: Proc. PHYSOR 2016, Sun Valley, Idaho, USA. pp. 3519-3531.

Alam, S.B., Lindley, B.A., Parks, G.T., Shwageraus, E., 2016c. Burnable poison designs for a soluble-boronfree civil nuclear marine PWR core, in: Proc. PHYSOR 2016, Sun Valley, Idaho, USA. pp. 1926-1938.

Alam, S.B., Mohamed, H., Lindley, B.A., Parks, G.T., 2016d. Analysis and design of a high power density marine PWR core using mixed $\mathrm{D}_{2} \mathrm{O}-\mathrm{H}_{2} \mathrm{O}$ coolant and checkerboard micro-heterogeneous $\mathrm{ThO}_{2}-\mathrm{UO}_{2}$ and all-uranium fuel, in: Proc. ICAPP 2016, San Francisco, California, USA. pp. 1678-1686.

Alam, S.B., Mohamed, H., Lindley, B.A., Parks, G.T., 2016e. Lattice design and coolant selection for a 333 MWth PWR civil marine propulsion core using checkerboard micro-heterogeneous $\mathrm{ThO}_{2}-\mathrm{UO}_{2}$ fuel, in: Proc. ICAPP 2016, San Francisco, California, USA. pp. 1687-1696.

Alam, S.B., de Oliveira, R.G., Goodwin, C.S., Parks, G.T., 2019d. Coupled neutronic/thermal-hydraulic hot channel analysis of high power density civil marine SMR cores. Annals of Nuclear Energy 127, 400-411.

Alam, S.B., Oliviera, R.D., Parks, G.T., Shwageraus, E., 2017b. Hot channel analysis of a 333 MWth high power density civil marine core using 3D neutronic/thermal-hydraulic coupling of hybrid monte carlo MONK with sub-channel analysis COBRA-EN code, in: Proc. ICAPP 2017, Fukui and Kyoto, Japan. pp. 17331-17340.

Alam, S.B., Parks, G.T., Lindley, B.A., 2016f. Hot assembly and whole-core thermal-hydraulic analysis of a high power density marine core with neutronic/thermal-hydraulic coupling, in: Proc. PHYSOR 2016, Sun Valley, Idaho, USA. pp. 3506-3518.

Alam, S.B., Ridwan, T., Parks, G.T., Almutairi, B., Goodwin, C.S., 2018c. High power density reactor core design for civil nuclear marine propulsion. Part I: Assembly-level analysis, in: Proc. PHYSOR 2018, Cancun, Mexico. pp. 46-57.

Alam, S.B., Ridwan, T., Parks, G.T., Almutairi, B., Goodwin, C.S., 2018d. High power density reactor core design for civil nuclear marine propulsion. Part II: Whole-core analysis, in: Proc. PHYSOR 2018, Cancun, Mexico. pp. 58-69.

Andrews, N., Pilat, E., Shirvan, K., Kazimi, M.S., 2014. Impact of SiC cladding on plutonium burning in a thorium fueled PWR, in: Proc. ICAPP 2014, Charlotte, USA.

Anger, A., 2010. Including aviation in the European emissions trading scheme: impacts on the industry, $\mathrm{CO}_{2}$ emissions and macroeconomic activity in the EU. J. Air Transp. Manag. 16, 100-105.

Aspelund, A., Molnvik, M., De Koeijer, G., 2006. Ship transport of $\mathrm{CO}_{2}$ : technical solutions and analysis of costs, energy utilization, energy efficiency and $\mathrm{CO}_{2}$ emissions. Chem. Eng. Res. Des. 84, 847-855.

Baldova, D., Fridman, E., Shwageraus, E., 2014. High conversion Th-U233 fuel for current generation of PWRs: Part II-3D full core analysis. Ann. Nucl. Energ. 73, 560-566.

Basile, D., 1999. COBRA-EN: An Upgraded Version of the COBRA-3C/MIT Code for Thermal-Hydraulic Transient Analysis of Light Water Reactor Fuel Assemblies and Cores. ENELCRTN, Milano, Italy. 
Björk, K.I., Fhager, V., Demazière, C., 2011. Comparison of thorium-based fuels with different fissile components in existing boiling water reactors. Prog. Nucl. Energy 53 (6), 618-625.

Brown, N.R., Worrall, A., Todosow, M., 2017. Impact of thermal spectrum small modular reactors on performance of once-through nuclear fuel cycles with low-enriched uranium. Annals of Nuclear Energy 101, 166-173.

Bukharin, O., 2006. Russia's nuclear icebreaker fleet. Sci. Global Secur. 14, 25-31.

Carlton, J., Smart, R., Jenkins, V., 2011. The nuclear propulsion of merchant ships: aspects of engineering, science and technology. J. Mar. Eng. Technol. 10, 47-59.

Casadei, A., Esposito, V., 1990. Advanced in-core fuel management methods at Westinghouse, in: In-core Fuel Management Practices. International Atomic Energy Agency, Vienna, Austria. IAEA-TECDOC-567, pp. 99-106.

Clayton, J., 1993. The Shippingport Pressurized Water Reactor and Light Water Breeder Reactor. Technical Report WAPD-T-3007. Westinghouse Electric Corporation, Bettis Atomic Power Laboratory. West Mifflin, Pennsylvania, USA.

Csom, G., Reiss, T., Fehér, S., Czifrus, S., 2012. Thorium as an alternative fuel for SCWRs. Ann. Nucl. Energy 41, 67-78.

Dedes, E., Turnock, S., Hudson, D., Hirdaris, S., 2011. Possible power train concepts for nuclear powered merchant ships, in: Proc. International Conference on Technologies, Logistics and Modelling for Low Carbon Shipping, Glasgow, UK. pp. 261-274.

Fan, H., 2012. The Conceptual Design of a Marine Propulsion Reactor Core. Master's thesis. Department of Engineering, University of Cambridge. Cambridge, UK.

Franceschini, F., Petrović, B., 2009. Fuel with advanced burnable absorbers design for the IRIS reactor core: Combined erbia and IFBA. Ann. Nucl. Energy 36, 1201-1207.

Fridman, E., Kliem, S., 2011. Pu recycling in a full Th-MOX PWR core. Part I: Steady state analysis. Nucl. Eng. Des. 241, 193-202.

Galperin, A., Shwageraus, E., Todosow, M., 2002. Assessment of homogeneous thorium/uranium fuel for Pressurized Water Reactors. Nucl. Technol. 138, 111-122.

György, H., Czifrus, S., 2015. Burnup calculation of the Generation IV reactors. Prog. Nucl. Energy 81, 150-160.

Haibach, B.V., Feltus, M.A., 1997. A study on the optimization of integral fuel burnable absorbers using deterministic methods. Ann. Nucl. Energy 24 (11), 835-846.

Hirdaris, S.E., Cheng, Y.F., Shallcross, P., Bonafoux, J., Carlson, D., Prince, B., Sarris, G.A., 2014a. Considerations on the potential use of nuclear small modular reactor technology for merchant marine propulsion. Ocean Engineering 79, 101-130.

Hirdaris, S.E., Cheng, Y.F., Shallcross, P., Bonafoux, J., Carlson, D., Sarris, G.A., 2014b. Concept design for a Suezmax tanker powered by a 70 MW SMR. International Journal of Maritime Engineering 156, 37-59.

House, D., 2015. Dry Docking and shipboard maintenance: a guide for industry. Taylor \& Francis, Newyork, USA.

Hutt, P., 1992. Overview Functional Specification of PANTHER: A Comprehensive Thermal Reactor Code for Use in Design, Assessment and Operation. PANTHER/FSPEC/OVERVIEW 2.0, Nuclear Electric plc, Barnwood, UK.

Ippolito, T.D., 1990. Effects of variation of uranium enrichment on nuclear submarine reactor design. Master's thesis. Massachusetts Institute of Technology.

Jagannathan, V., Pal, U., Karthikeyan, R., Raj, D., Srivastava, A., Khan, S.A., 2008. Reactor physics ideas to design novel reactors with faster fissile growth. Energy Convers. Manage. 49, 2032-2046.

Kazimi, M., Czerwinski, K., Driscoll, M., Hejzlar, P., Meyer, J., 1999. On the Use of Thorium in Light Water Reactors. Technical Report MIT-NFCTR-016. Department of Nuclear Engineering, Massachusetts Institute of Technology. Boston, Massachusetts, USA.

Khlopkin, N., Zotov, A., 1997. Merchant marine nuclear-powered vessels. Nucl. Eng. Des. 173, 201-205.

Kim, J.C., Kim, M.H., Lee, U., Kim, Y.J., 1998. Nuclear design feasibility of the soluble boron free PWR core. J. Korean Nucl. Soc. 30, 342-352. 
Kim, S.Y., Kim, J.K., 2000. A reactivity hold-down strategy for soluble boron free operation by introducing Pu-238 added fuel. Ann. Nucl. Energy 27, 855-871.

Kramer, A., 1962. Nuclear Propulsion for Merchant Ships. US Atomic Energy Commission, Washington, DC, USA.

Kusunoki, T., Odano, N., Yoritsune, T., Ishida, T., Hoshi, T., Sako, K., 2000. Design of advanced integral-type marine reactor, MRX. Nucl. Eng. Des. 201, 155-175.

Lau, C.W., Demazière, C., Nylén, H., Sandberg, U., 2012. Improvement of LWR thermal margins by introducing thorium. Prog. Nucl. Energy 61, 48-56.

Leppänen, J., Pusa, M., 2009. Burnup calculation capability in the PSG2/Serpent Monte Carlo reactor physics code, in: Proc. International Conference on Advances in Mathematics, Computational Methods, and Reactor Physics, Saratoga Springs, New York, USA.

Liu, S., Cai, J., 2013. Neutronics assessment of thorium-based fuel assembly in SCWR. Nucl. Eng. Des. 260, $1-10$.

Liu, S., Cai, J., 2014. Design \& optimization of two breeding thorium-uranium mixed SCWR fuel assemblies. Prog. Nucl. Energy 70, 6-19.

Long, D., Richards, S., Smith, P., Baker, C., Bird, A., Davies, N., Dobson, G., Fry, T., Hanlon, D., Perry, R., Shepherd, M., 2015. MONK10: A Monte Carlo code for criticality analysis, in: Proc. International Conference on Nuclear Criticality Safety (ICNC 2015), Charlotte, North Carolina, USA. pp. 923-935.

MacDonald, P., Lee, C., 2004. Use of thoria-urania fuels in PWRs: A general review of a NERI project to assess feasible core designs, economics, fabrication methods, in-pile thermal/mechanical behavior, and waste form characteristics. Nucl. Technol. 147, 1-7.

McCord, C., 2013. Examination of the proposed conversion of the US Navy nuclear fleet from highly enriched Uranium to low enriched Uranium. Master's thesis. Massachusetts Institute of Technology.

Mitenkov, F., Yakovlev, O., Polunichev, V., Panov, Y.K., Ruksha, V., Golovinskii, S., Kashka, M., 2003. Prospects for using nuclear power systems in commercial ships in northern Russia. Atom. Energy 94, 211-216.

Namikawa, S., Mærli, M., Hoffmann, P., Brodin, E., 2011. Nuclear powered ships-findings from a feasibility study, in: Proc. 19th International Conference on Nuclear Engineering (ICONE19), Chiba, Japan.

Newton, T., Hosking, G., Hutton, L., Powney, D., Turland, B., Shuttleworth, E., 2008. Developments within WIMS10, in: Proc. PHYSOR 2008, Interlaken, Switzerland.

Norton, E., Mrina, M.I., 1962. Modern trends in marine propulsion machinery. Nav. Eng. J. 74, $723-732$.

Otto, R.T., 2013. Core Optimization in a Thorium-based Civil Marine Propulsion Reactor. Master's thesis. Department of Engineering, University of Cambridge.

Peakman, A., 2014. Development of a Long-Life Core for Commercial Marine Propulsion. Ph.D. thesis. University of Manchester. Manchester, UK.

Powers, J.J., George, N., Maldonado, G.I., Worrall, A., 2015. Report on Reactor Physics Assessment of Candidate Accident Tolerant Fuel Cladding Materials in LWRs. Oak Ridge National Laboratory, Tennessee, USA.

Pramuditya, S., Takahashi, M., 2013. Core design study for power uprating of integral primary system PWR. Ann. Nucl. Energy 59, 16-24.

Prasad, S., Abdulla, A., Morgan, M.G., Azevedo, I.L., 2015. Nonproliferation improvements and challenges presented by small modular reactors. Prog. Nucl. Energy 80, 102-109.

Ragheb, M., 2011. Nuclear naval propulsion, in: Tsvetkov, P. (Ed.), Nuclear Power - Deployment, Operation and Sustainability. InTech, Rijeka, Croatia. chapter 1, pp. 3-32.

Rossiter, G., M., M., 2011. The characteristics of LWR fuel at high burnup and their relevance to AGR spent fuel. National Nuclear Laboratory, Sellafield, UK.

Sawyer, G., Shirley, J., Stroud, J., Barlett, E., McKesson, C., 2008. Analysis of high-speed trans-pacific nuclear containership service. USA: General Management Partners LLC .

Schinas, O., Stefanakos, C.N., 2012. Cost assessment of environmental regulation and options for marine operators. Transport. Res. C-Emer. 25, 81-99.

Shaposhnik, Y., Shwageraus, E., Elias, E., 2014. Shutdown margin for high conversion BWRs operating in 
Th-U233 fuel cycle. Nucl. Eng. Des. 276, 162-177.

Shwageraus, E., Feinroth, H., 2011. Potential of silicon carbide cladding to extend burnup of pu-th mixed oxide fuel. Transactions of the American Nuclear Society 104, 658-660.

Shwageraus, E., Zhao, X., Driscoll, M.J., Hejzlar, P., Kazimi, M.S., Herring, J.S., 2004. Microheterogeneous thoria-urania fuels for pressurized water reactors. Nucl. Technol. 147, 20-36.

Smith, P., Lillington, J., Middlemas, C., 2011. Radiation transport modelling and the ANSWERS codes suite. Nucl. Future 7, 44-49.

Sukjai, Y., Kazimi, M.S., 2015. Performance of thoria fuels and SiC cladding for burning of plutonium in pressurized water reactors, in: Proc. ANFM 2015, Hilton Head Island, SC, USA.

Sun, H., 2014. Marine Reactor Core Physics Study. Master's thesis. Department of Engineering, University of Cambridge. Cambridge, UK.

Todosow, M., Galperin, A., Herring, S., Kazimi, M., Downar, T., Morozov, A., 2005. Use of thorium in light water reactors. Nucl. Technol. 151, 168-176.

Tsige-Tamirat, H., 2011. Neutronics assessment of the use of thorium fuels in current pressurized water reactors. Prog. Nucl. Energy 53, 717-721.

Vergara, J.A., McKesson, C.B., 2002. Nuclear propulsion in high-performance cargo vessels. Mar. Technol. $39,1-11$.

Winters, J.W., 2004. AP1000 Design Control Document. Westinghouse Electric Company LLC, Pittsburgh, Pennsylvania, USA.

Wu, X., Sabharwall, P., Hales, J., Kozlowski, T., 2014. Neutronics and fuel performance evaluation of accident tolerant fuel under normal operation conditions. Idaho National Laboratory, Idaho Falls, Idaho Falls, USA.

Xu, Z., 2003. Design strategies for optimizing high burnup fuel in Pressurized Water Reactors. Ph.D. thesis. Massachusetts Institute of Technology.

Yoo, H.S., Hong, S.G., 2018. Neutronic design and analysis of advanced long-cycle boron-free operation of a small modular reactor core with particle type burnable poison rods. International Journal of Energy Research 42, 4654-4666.

Zainuddin, N.Z., 2015. In-core Optimisation of Thorium-Plutonium-fuelled PWR Cores. Ph.D. thesis. University of Cambridge.

Zainuddin, N.Z., Lindley, B.A., 2014. Notes on WIMS, WIMSbuilder and PANTHER. University of Cambridge, Cambridge, UK.

Zainuddin, N.Z., Lindley, B.A., Parks, G.T., 2013. Towards optimal in-core fuel management of ThoriumPlutonium-fuelled PWR cores, in: Proc. 21st International Conference on Nuclear Engineering (ICONE21), Chengdu, China.

Zhang, J., 2013. Commercial Nuclear Marine Reactor Physics Design for Uranium Fuel. Master's thesis. Department of Engineering, University of Cambridge. Cambridge, UK.

Zhao, X., 2001. Micro-heterogeneous Thorium Based Fuel Concepts for Pressurized Water Reactors. Ph.D. thesis. Massachusetts Institute of Technology.

Zverev, D., Pakhomov, A., Polunichev, V., Veshnyakov, K., Kabin, S., 2013. RITM-200: new-generation reactor for a new nuclear icebreaker. At. Energ. 113, 404-409. 